Revista Brasil. Bot., V.32, n.2, p.189-211, abr.-jun. 2009

\title{
Novas ocorrências de antóceros e hepáticas para o Estado do Rio Grande do Sul, Brasil ${ }^{1}$
}

\author{
JUÇARA BORDIN ${ }^{2,3}$ e OLGA YANO ${ }^{2}$
}

(recebido: 17 de janeiro de 2008; aceito: 22 de janeiro de 2009)

\begin{abstract}
New occurrences of hornworts and liverworts from Rio Grande do Sul State, Brazil). Twenty two taxa (1 hornwort and 21 liverworts) were identified with new records to Rio Grande do Sul State. Eight families and 15 genera belong to Marchantiophyta and one genus and one family belong to Anthocerotophyta. The most representative families are Lejeuneaceae, Aneuraceae and Metzgeriaceae. Neesioscyphus argillaceus (Nees) Grolle and Lejeunea cancellata Nees \& Mont. were cited for new sites. All species are illustrated and geographic distributions are presented.
\end{abstract}

Key words - Anthocerotophyta, Marchantiophyta, new records, Rio Grande do Sul

RESUMO - (Novas ocorrências de antóceros e hepáticas para o Estado do Rio Grande do Sul, Brasil). Foram identificados 22 táxons de antóceros e hepáticas que são novas ocorrências para o Estado do Rio Grande do Sul (1 antócero e 21 hepáticas). Oito famílias e 15 gêneros pertencem à Marchantiophyta e um gênero e uma família à Anthocerotophyta. As famílias mais bem representadas são Lejeuneaceae, Aneuraceae e Metzgeriaceae. Neesioscyphus argillaceus (Nees) Grolle e Lejeunea cancellata Nees \& Mont. tiveram sua distribuição geográfica ampliada. Estão sendo apresentadas ilustrações e distribuição geográfica para todos os táxons.

Palavras-chave - Anthocerotophyta, Marchantiophyta, novas citações, Rio Grande do Sul

\section{Introdução}

O Estado do Rio Grande do Sul corresponde à porção mais meridional do Brasil, localizado na Zona Temperada Sul, entre o Trópico de Capricórnio e o Círculo Polar Antártico, com latitude média de $30^{\circ} \mathrm{Sul}$ e área total de $282.680 \mathrm{~km}^{2}$ (Fortes 1956). O clima, segundo o sistema de Köppen, se enquadra na zona fundamental temperada ou "C" e no tipo fundamental "Cf" ou temperado úmido (Moreno 1961).

A vegetação do Estado compreende nove regiões fitogeográficas: Floresta Ombrófila Densa, Floresta Ombrófila Mista, Floresta Estacional Semidecidual, Floresta Estacional Decidual, Savana, Estepe, Savana Estépica, Áreas de formações pioneiras e influência marinha e Áreas de tensão ecológica (Leite \& Klein 1990), sendo que $131.896 \mathrm{~km}^{2}(46,26 \%)$ da área total do Estado corresponde aos campos, $98.327 \mathrm{~km}^{2}(34,47 \%)$ às matas e o restante à vegetação litorânea, banhados inundáveis e outras formações (Rambo 1956).

Diversos botânicos passaram pelo Rio Grande do Sul com o objetivo de explorar as plantas vasculares, entretanto, apenas Lindman, Saint-Hilaire e Sellow

\footnotetext{
1. Parte da Dissertação de Mestrado da primeira Autora, Programa de Pós-Graduação em Biodiversidade Vegetal e Meio Ambiente, Instituto de Botânica, São Paulo.

2. Instituto de Botânica, Caixa Postal 3005, 01061-970 São Paulo, SP, Brasil.

3._Autor para correspondência: jucarabordin@gmail.com
}

coletaram briófitas (Bordin 2008). Os registros mais antigos que se referem à hepáticas e antóceros para o Estado são de Montagne (1838), citando uma hepática coletada por Saint-Hilaire e de Lindman (1906), que mencionou 24 hepáticas e um antócero em sua obra $A$ vegetação do Rio Grande do Sul.

Posteriormente, Baptista (1977) iniciou os estudos das hepáticas publicando um guia para os gêneros da família Lejeuneaceae na Flora ilustrada do Rio Grande do Sul; Bueno $(1984,1986)$ publicou trabalhos referentes a gêneros de Jungermanniales, exceto Lejeuneaceae e ao gênero Balantiopsis; Lemos-Michel (1980, 1983, 2001) trabalhou com diversos grupos de hepáticas; Lemos-Michel \& Yano (1998) estudaram o gênero Bryopteris; Lemos-Michel \& Bueno (1992) publicaram sobre o gênero Bazzania; Lorscheitter (1973, 1977) trabalhou com hepáticas folhosas; Oliveira (1973) estudou as espécies de Radula; Vianna (1970, 1971, 1976, 1981a, 1981b, 1981c, 1985, 1988, 1990), estudou as hepáticas talosas e, recentemente, Yano \& Bordin (2006) e Peralta et al. (2008), citaram algumas novas ocorrências de hepáticas para o Rio Grande do Sul.

Com relação aos trabalhos relacionados à briófitas que se desenvolvem em áreas urbanas, apesar da grande importância, há poucas referências no Brasil (Câmara et al. 2003), não sendo mencionado nenhum para a região Sul.

Atualmente são conhecidas para o Estado três espécies de antóceros e 180 de hepáticas, com base em Yano (2008) 
e Peralta et al. (2008), o que corresponde à $17 \%$ do total de espécies conhecidas para o Brasil.

O objetivo deste trabalho é ampliar o conhecimento da distribuição geográfica das espécies e melhor conhecer a diversidade de antóceros e hepáticas do Estado, especialmente em áreas urbanas.

\section{Material e métodos}

O estudo foi desenvolvido no centro urbano do município de Caxias do Sul $\left(51^{\circ} 00^{\prime} \mathrm{W}, 2^{\circ} 30^{\prime} \mathrm{S}\right)$, localizado na extremidade leste da Encosta Superior do Nordeste do Estado do Rio Grande do Sul. Possui área de 1.643,913 km², chuvas bem distribuídas ao longo do ano e vegetação formada pela Floresta Ombrófila Mista, Savana Gramíneo-Lenhosa e Floresta Estacional Decidual (Veloso et al. 1991).

As coletas foram realizadas no período de agosto de 2005 a novembro de 2006. O método de coleta, preservação e herborização foi baseado em Yano (1984b) e a distribuição geográfica em Yano (2008), Peralta et al. (2008) e outros trabalhos mais recentes.

O sistema de classificação utilizado foi o de Stotler \& Crandall-Stotler (2005) para Anthocerotophyta e CrandallStotler \& Stotler (2000) para Marchantiophyta.

Para identificação das espécies foram utilizados os trabalhos de: Bastos (2004), Costa (1999), Fulford (1976), Gradstein (1975, 1994), Gradstein \& Costa (2003), Hässelde-Menéndez (1962, 1989), Heinrichs \& Gradstein (2000), Hell (1969), Oliveira-e-Silva \& Yano (2000) Reiner-Drehwald (2000), Schuster (1980, 1992), Yamada (1982) e Yano et al. (2003).

As amostras foram depositadas no Herbário Científico do Estado "Maria Eneyda P. Kauffmann Fidalgo" (SP), com duplicatas no Herbário da Universidade de Caxias do Sul (HUCS).

Os táxons estão listados em ordem alfabética de família, gênero e espécie, dentro de cada divisão, sendo apresentado para cada um, material examinado, distribuição geográfica no Brasil, comentários e ilustração.

\section{Resultados}

Para o Estado do Rio Grande do Sul foram citados 22 táxons (1 antócero e 21 hepáticas), como novas ocorrências, distribuídos em oito famílias e 15 gêneros de hepáticas e uma família e um gênero de antócero. As famílias mais bem representadas são Lejeuneaceae (7 gêneros e 12 espécies), Aneuraceae (1 gênero e 2 espécies) e Metzgeriaceae (1 gênero e 2 espécies). Neesioscyphus argillaceus (Nees) Grolle e Lejeunea cancellata Nees \& Mont. tiveram a distribuição geográfica ampliada para o município de Caxias do Sul, sendo citados pela primeira vez em área urbana.
São referidas para a primeira vez para a região Sul as seguintes espécies: Drepanolejeunea anoplantha (Spruce) Steph., Fossombronia porphyrorhiza (Nees) Prosk., Lejeunea setiloba Spruce, Noteroclada confluens (Hook. f. \& Taylor) Spruce, Phaeoceros bulbiculosus (Brot.) Prosk. e Plagiochila montagnei Nees.

Lejeunea glaucescens Gottsche, Lopholejeunea nigricans (Lindenb.) Schiffn., Metzgeria psilocraspeda Schiffn., Metzgeria uncigera A. Evans e Microlejeunea bullata (Taylor) Steph. já haviam sido referidos para os Estados de Santa Catarina e Paraná, portanto, esta citação para o Rio Grande do Sul, cobre uma importante lacuna na distribuição geográfica destes táxons.

\section{ANTHOCEROTOPHYTA}

\section{NOTOTHYLADACEAE}

Phaeoceros bulbiculosus (Brot.) Prosk., Rapp. Comm. VIII Congr. Inst. Bot. Paris: 69. 1954. $\equiv$ Anthoceros bulbiculosus Brot., Flora Ibérica 2:430. 1804.

Figura 1
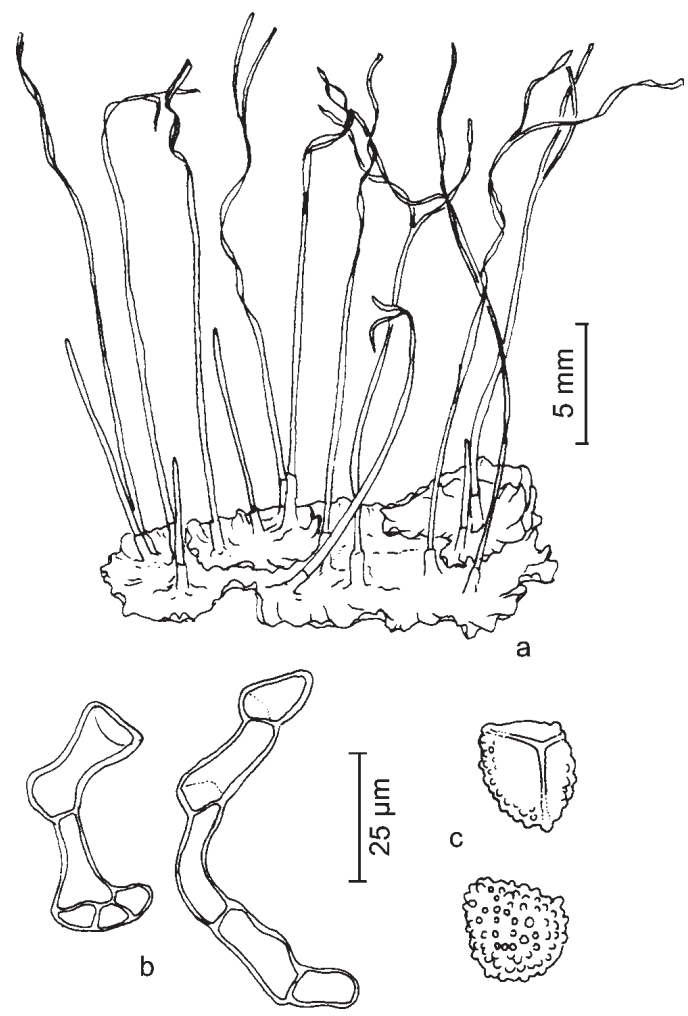

Figura 1. Phaeoceros bulbiculosus. a. Aspecto geral do gametófito com esporófitos. b. Pseudoelatérios. c. Esporos (O. Yano \& J. Bordin 29201, SP385666).

Figure 1. Phaeoceros bulbiculosus. a. Habit of gametophyte with sporophytes. b. Pseudoelateres. c. Spore (O. Yano \& J. Bordin 29201, SP385666). 
Material examinado: BRASIL. Rio GRANDE Do Sul: Caxias do Sul, Parque dos Macaquinhos, no solo úmido, 6-X-2006, O. Yano \& J. Bordin 29201 (SP385666).

Distribuição no Brasil: SP.

Comentários: reconhecida pelos esporos amarelados, com superfície lisa, pseudo-elatérios pardopálidos, com 1-4(-5) células irregularmente curvadas, de paredes delgadas. Ocorre no solo úmido e rochas, até $800 \mathrm{~m}$ de altitude (Gradstein \& Costa 2003). Foi coletado em área antropizada, no solo úmido.

Até o momento a espécie era conhecida apenas para o Estado de São Paulo (Yano 2008). Esta é uma referência importante pois se trata da segunda citação para o Brasil, indicando que a espécie também pode ocorrer em outras localidades.

\section{MARCHANTIOPHYTA}

\section{ANEURACEAE}

Riccardia cataractarum (Spruce) K. G. Hell, Bolm. Univ. São Paulo 335, Bot. 25:97. 1969. 三Aneura cataractarum Spruce, Bull. Soc. Bot. France 36 (suppl.):195. 1889. Figura 2
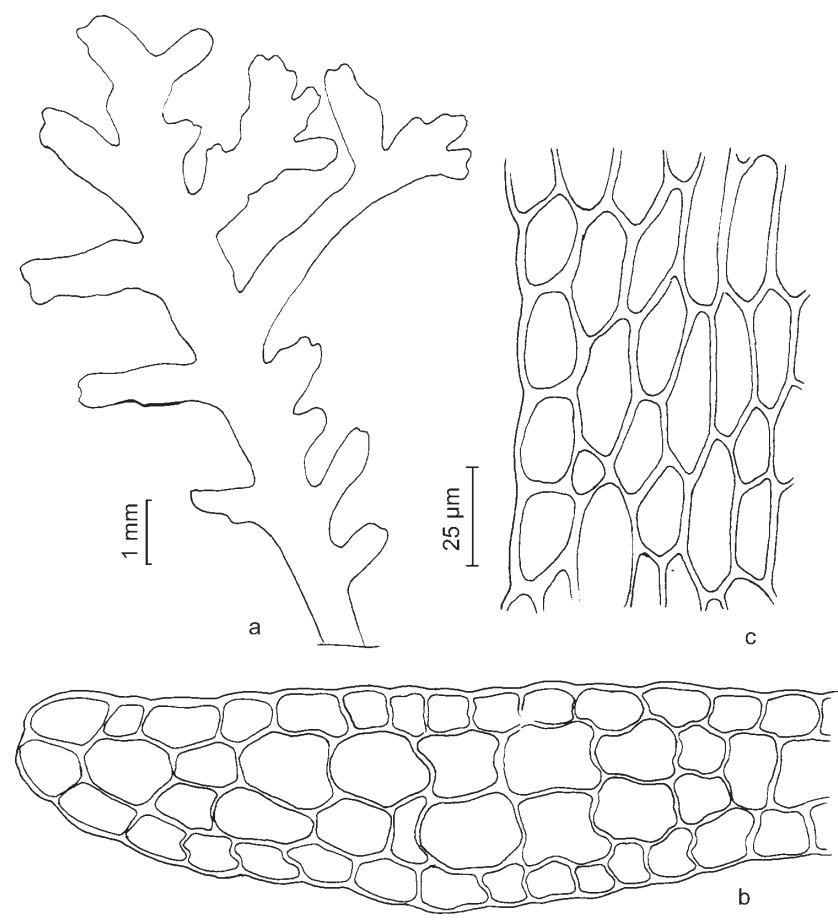

Figura 2. Riccardia cataractarum. a. Aspecto geral do gametófito. b. Secção transversal do talo. c. Células da margem do talo (E. Pasini 60, SP383060).

Figura 2. Riccardia cataractarum. a. Habit of gametophyte. b. Cross section of thallus. c. Marginal cells of thallus (E. Pasini 60, SP383060).
Material examinado: BRASIL. Rio GRANDE do SuL: Caxias do Sul, Jardim Botânico de Caxias do Sul, sobre troncos, 18-IV-2006, E. Pasini 60 (HUCS28207, SP383060).

Distribuição no Brasil: DF, ES, GO, MG, MS, MT, RJ, SC e SP.

Comentários: reconhecida pelo gametófito bem aderido ao substrato, irregularmente ramificado, com rizóides na margem do talo curtos e abundantes, sem nervura e pela secção transversal do eixo principal do gametófito com células centrais grandes, rombohexagonais em 5-6 camadas, diferenciadas na margem, menores, curto-retangulares.

Difere de Riccardia chamedryfolia (With.) Grolle, pois esta apresenta gametófitos verde-claros, brilhantes, secção transversal do talo plano-convexa e ausência de rizóides.

Cresce sobre barrancos, rochas ou entre gravetos em decomposição, em lugares muito úmidos, freqüentemente onde corre água, ficando muitas vezes submersa formando pequenas placas que se entrelaçam com outras plantas que crescem no local (Hell 1969).

Riccardia chamedryfolia (With.) Grolle, Trans. Brit. Bryol. Soc. 5:772. 1969. 三 Jungermania chamedryfolia With., Bot. Arr. Veg. Great Britain 2:699. 1776.

Figura 3

Material examinado: BRASIL. Rio GRANDE do SuL: Caxias do Sul, Parque dos Macaquinhos, no barranco úmido, 6-X-2006, O. Yano \& J. Bordin 29238p.p. (HUCS29586, SP385703).

Distribuição no Brasil: AC, AM, BA, DF, ES, MG, MT, RJ, SC e SP.

Comentários: reconhecida pelo gametófito com muitas ramificações curtas, ausência de rizóides na margem do talo e pela secção transversal do eixo principal do gametófito plano-convexa, com 5-7 camadas de células e 1-2 células nas bordas, sem células diferenciadas na margem.

Difere de Riccardia cataractarum, pois esta apresenta gametófitos verde-escuros a marrons; secção transversal do talo quase paralela e rizóides curtos na margem.

Cresce em barrancos ou rochas próximas de rios, aderidas ao substrato (Costa \& Yano 1988), às vezes totalmente submersa e sempre em lugares molhados (Hell 1969). Foi coletada em barranco úmido, associada a Fissidens angustifolius Sull.

A nova ocorrência desta espécie, assim como de $R$. cataractarum (Spruce) K. G. Hell, era esperada para o 


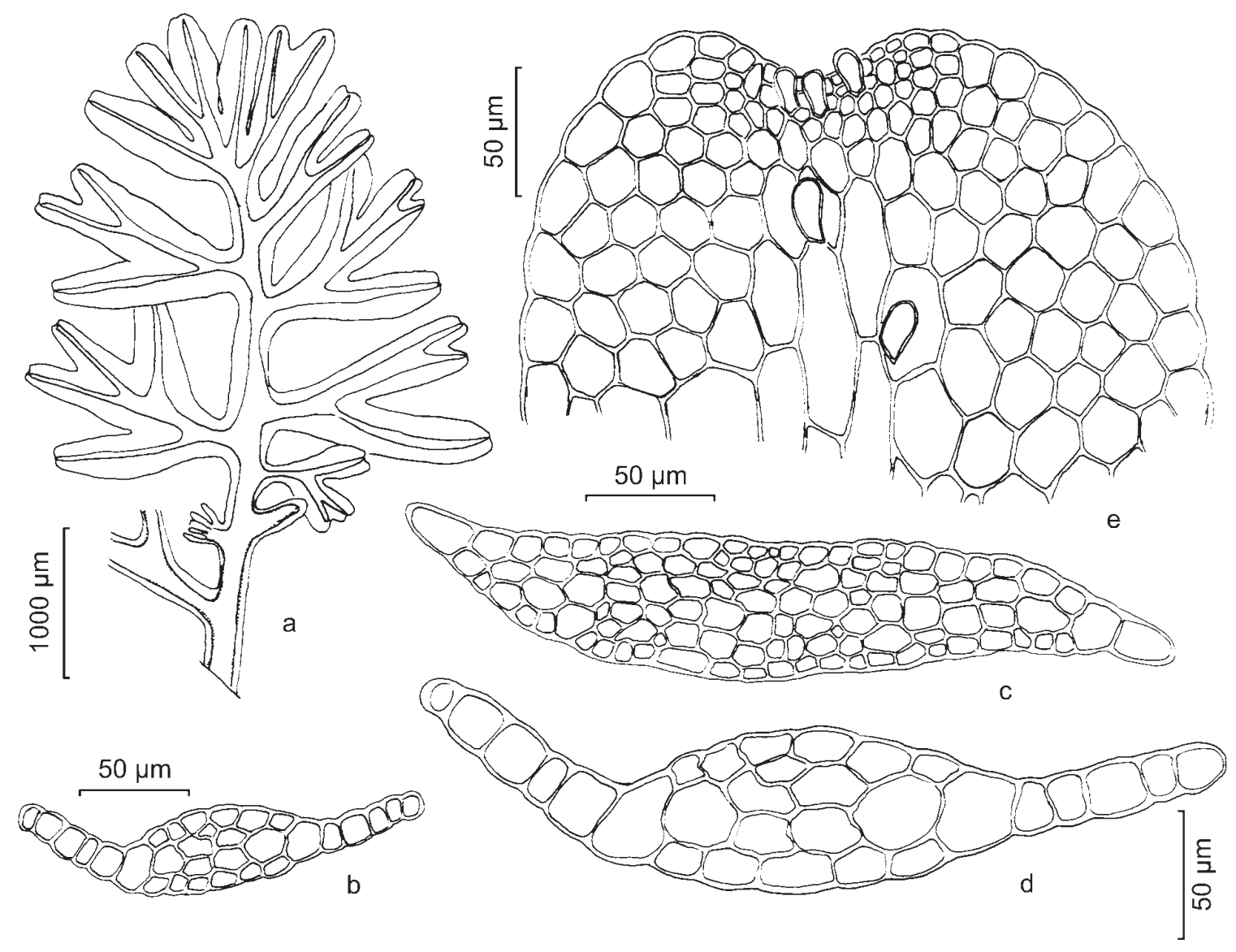

Figura 3. Riccardia chamedryfolia. a. Aspecto geral do gametófito. b, c, d. Secção transversal do talo. e. Células do ápice do talo com papilas mucilaginíferas (D.F. Peralta 2212, SP368629).

Figure 3. Riccardia chamedryfolia. a. Habit of gametophyte. b, c, d. Cross section of thallus. e. Cells of thallus apex with slime papillae (D.F. Peralta 2212, SP368629).

Estado, uma vez que estas espécies já ocorrem em Santa Catarina e possuem uma ampla distribuição em diversos outros Estados brasileiros.

\section{BALANTIOPSIDACEAE}

Neesioscyphus argillaceus (Nees) Grolle, Österr. Bot. Zeitschr. 111:24. 1964. 三Jungermannia argillacea Nees in Martius, Flora Brasil. enum. plant. 1(1):338. 1833. Figura 4

Material examinado: BRASIL, Rio GRANDE do SuL: Caxias do Sul, Universidade de Caxias do Sul, no barranco, 4-X-2006, O. Yano \& J. Bordin 29127 (HUCS29529, SP385505).

Distribuição no Brasil: DF, ES, GO, MG, MT, RJ, RS (Caxias do Sul, Travessão Gablontz) e SP.

Comentários: reconhecida pela coloração verde-clara, filídios distantes, côncavos, desigualmente bilobados e anfigastros reduzidos, bífidos, assimétricos.
Ocorre em terras íngremes e ao longo de estradas, até $1.000 \mathrm{~m}$ de altitude (Gradstein \& Costa 2003). Foi coletada sobre barranco, na mata.

Peralta et al. (2008) citaram esta espécie para o interior do município de Caxias do Sul (Travessão Gablontz), em área de Floresta Ombrófila Mista. Esta nova citação, em área urbana, amplia a distribuição geográfica deste táxon, confirmando que o mesmo é bastante comum, porém pouco coletado.

\section{FOSSOMBRONIACEAE}

Fossombronia porphyrorhiza (Nees) Prosk., Bryologist 58(3):197. 1955. $\equiv$ Jungermannia porphyrorhiza Nees in Martius, Flora Brasil. enum. plant. 1(1):343. 1833. Figura 5

Material examinado:BRASIL. RIoGRANDEDoSUL: Caxias do Sul, Parque Cinquientenário, sobre paredão de rocha úmida, 3-X-2006, O. Yano \& J. Bordin 29048 (SP383809). 
Distribuição no Brasil: BA, CE, DF, ES, GO, MG, MS, MT, PE, RJ e SP.

Comentários: reconhecida pelos gametófitos claros, em pequenas rosetas, com numerosos rizóides purpúreos, longos na face ventral.

Destaca-se pela reprodução vegetativa por meio de gemas originadas na superfície dorso-lateral do caulídio e ocorre em solo ou rochas, em lugares abertos, freqüentemente ao longo de rodovias, até $1.000 \mathrm{~m}$ de altitude (Gradstein \& Costa 2003). Foi coletada sobre rochas úmidas, em área antropizada.

Esta é a primeira citação da espécie para a região Sul do Brasil, pois até o momento sua distribuição ocorria do Ceará até São Paulo, não chegando aos Estados do Sul.

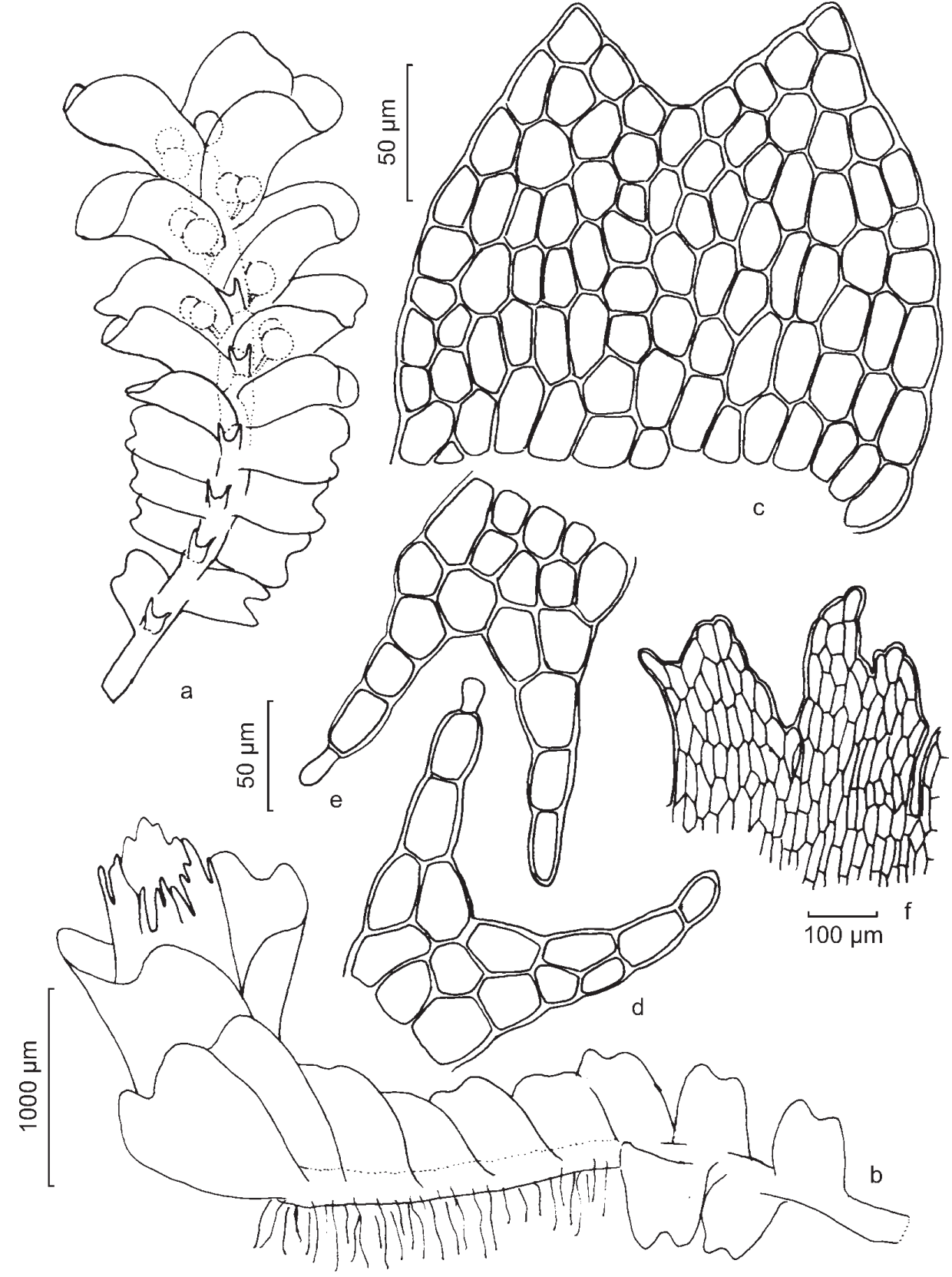

Figura 4. Neesioscyphus argillaceus. a. Aspecto geral do gametófito masculino. b. Aspecto geral do gametófito feminino. c. Lobo do filídio bífido. d,e. Anfigastros. f. Ápice do perianto (D.F. Peralta 1601, SP368414).

Figure 4. Neesioscyphus argillaceus. a. Habit of male gametophyte. b. Habit of female gametophyte. c. Bifid leaf lobe. d, e. Underleaves. f. Perianth apex (D.F. Peralta 1601, SP368414). 


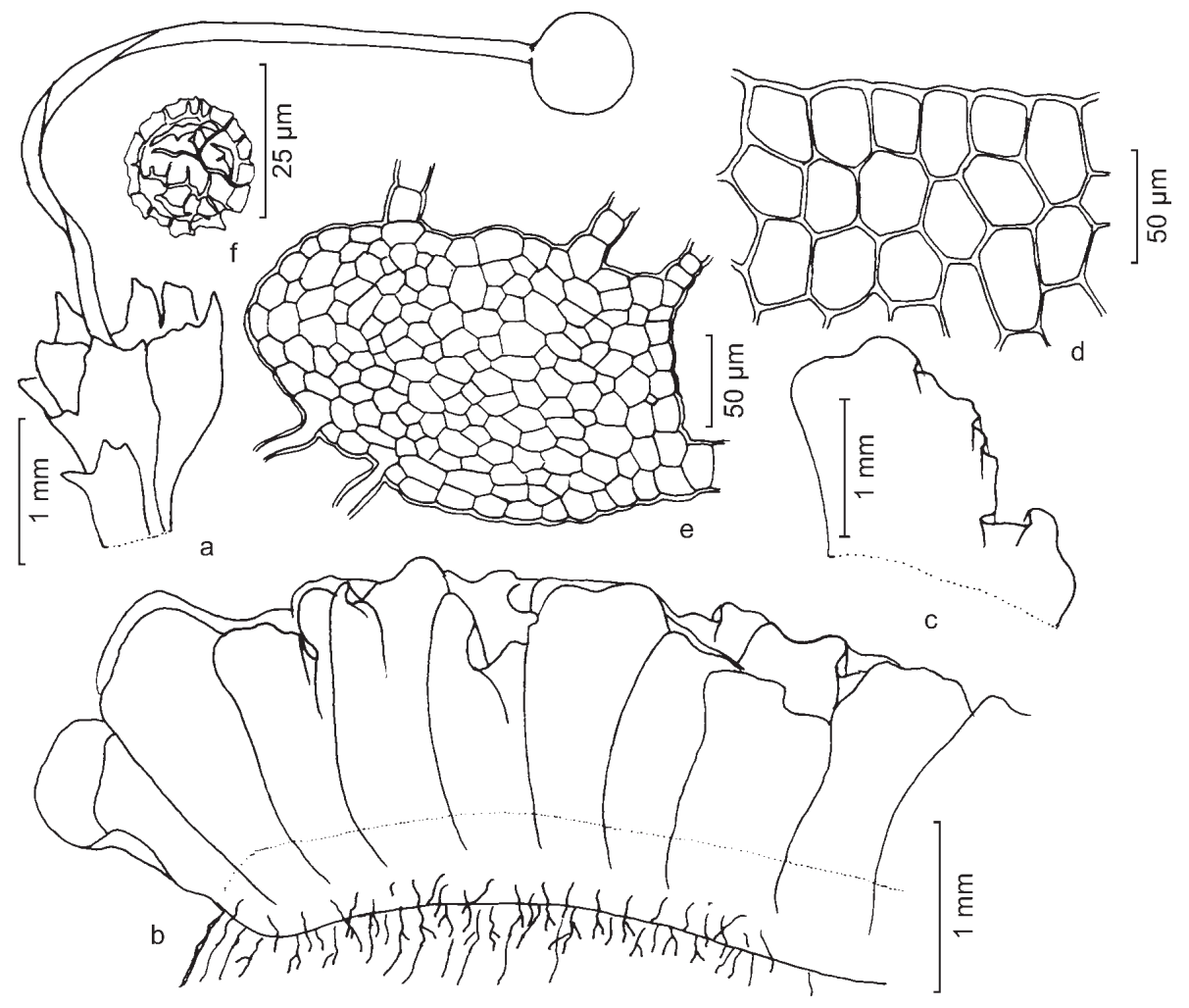

Figura 5. Fossombronia porphyrorhiza. a. Aspecto geral do gametófito com esporófito. b. Aspecto geral do gametófito em vista lateral. c. Lobo do filídio. d. Células do lobo do filídio. e. Secção transversal do talo. f. Esporo (D.M. Vital 3027, SP88452).

Figure 5. Fossombronia porphyrorhiza. a. Habit of gametophyte with sporophyte. b. Habit of gametophyte, lateral view. c. Leaf lobe. d. Cells of leaf lobe. e. Cross section of thallus. f. Spore (D.M. Vital 3027, SP88452).

\section{GEOCALYCACEAE}

Lophocolea platensis C. Massal., Atti Acad. Sci. Med. Nat. Ferrara 80(3-4):12. 1906.

Figura 6

Material examinado: BRASIL. RIo GRANDE Do SUL: Caxias do Sul, Parque dos Macaquinhos, no barranco úmido, 6-X-2006, O. Yano \& J. Bordin 29202, 29204, 29209 (SP385667; SP385669; HUCS29572, SP385674); Universidade de Caxias do Sul, no barranco, sobre rocha alterada, 4-X-2006, O. Yano \& J. Bordin 29128 (HUCS29530, SP385506); Jardim Botânico de Caxias do Sul, beira do riacho, barranco, 4-X-2006, O. Yano \& J. Bordin 29192 (HUCS29543, SP385570).

Distribuição no Brasil: BA, ES, GO, MT, SC e SP.

Comentários: reconhecida pelos filídios inteiros, arredondados e imbricados, côncavos em vista dorsal e pelo anfigastro duplamente bífido, mais longo do que largo, com 1-2 dentes laterais curtos.

Gradstein \& Costa (2003), citam L. platensis para o Rio Grande do Sul pois consideram que o material brasileiro de L. platensis foi previamente identificado por

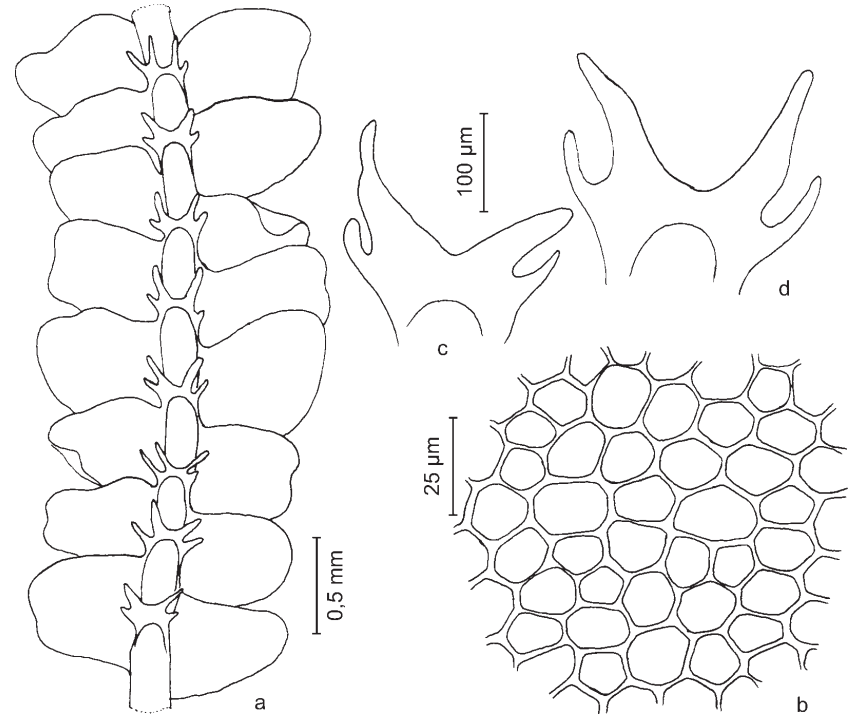

Figura 6. Lophocolea platensis. a. Aspecto geral do gemetófito, vista ventral. b. Células do lobo. c, d. Anfigastros. (D.M. Vital 2234, SP88003).

Figure 6. Lophocolea platensis. a. Habit of gametophyte, ventral view. b. Cells of lobe. c, d. Underleaves (D.M. Vital 2234, SP88003). 
Fulford (1976) como L. semiteres (Lehm.) Mitt. Grolle (1985), diferencia claramente L. platensis de $L$. semiteres, citando apenas a ocorrência da primeira para o Brasil.

Aceitando as diferenças entre $L$. platensis e $L$. semiteres propostas por Grolle (1985), considera-se $L$. platensis como citação nova para o Rio Grande do Sul, enfatizando que o material brasileiro de $L$. semiteres, examinado por Fulford (1976), não foi visto para fins de comparação.

É uma espécie comum e ocorre no solo, rochas, troncos de árvores ou raízes, até $1.000 \mathrm{~m}$ de altitude (Gradstein \& Costa 2003). Foi coletada sobre solo e rochas, em parques e na mata, sempre em locais úmidos.

\section{LEJEUNEACEAE}

Acanthocoleus trigonus (Nees \& Mont.) Gradst., Contr. Bot. Univ. Michigan Herb. 18:101. 1992. इ Lejeunea trigona Nees \& Mont., Ann. Sci. Nat. Bot. ser. 2, 5:61. 1836.

Figura 7

Material examinado: BRASIL. Rio GRANDE do Sul: Caxias do Sul, Parque dos Macaquinhos, no solo úmido, 6-X-2006, O. Yano \& J. Bordin 29232 (SP385697).

Distribuição no Brasil: SC e SP.

Comentários: reconhecida pela coloração verdeescura do gametófito, filídios com lobos ovalados, apiculados, lóbulos reduzidos, trigônios cordados e anfigastros inteiros, orbiculares.

Ocorre sobre rochas ao longo de riachos, bosques e matas semi-decíduas e em áreas com uma estação seca prolongada, $c a$. $1.000 \mathrm{~m}$ de altitude (Gradstein \& Costa 2003). Foi coletada em área úmida, antropizada.

Esta nova citação amplia a distribuição geográfica da espécie no Brasil, pois a mesma era conhecida apenas para os Estados de Santa Catarina e São Paulo (Yano 2008).

Acrolejeunea torulosa (Lehm. \& Lindenb.) Schiffn. in Engler \& Prantl, Natürl. Pflanzenfam. ed. 1, 3(1):128. 1893. $\equiv$ Jungermannia torulosa Lehm. \& Lindenb. in Lehmann, Nov. Min. Cogn. Stirp. Pugillus 6:41. 1834. Figura 8

Material examinado: BRASIL. Rio GRANDE do Sul: Caxias do Sul, Universidade de Caxias do Sul, na mata, base de tronco de Araucaria angustifolia, 3-XII-2005, J. Bordin \& L. Bordin 169p.p. (HUCS27200, SP379852); idem, sobre troncos, 22-XII-2005, J. Bordin et al. 208p.p. (HUCS27264, SP379859); idem, Zoológico,

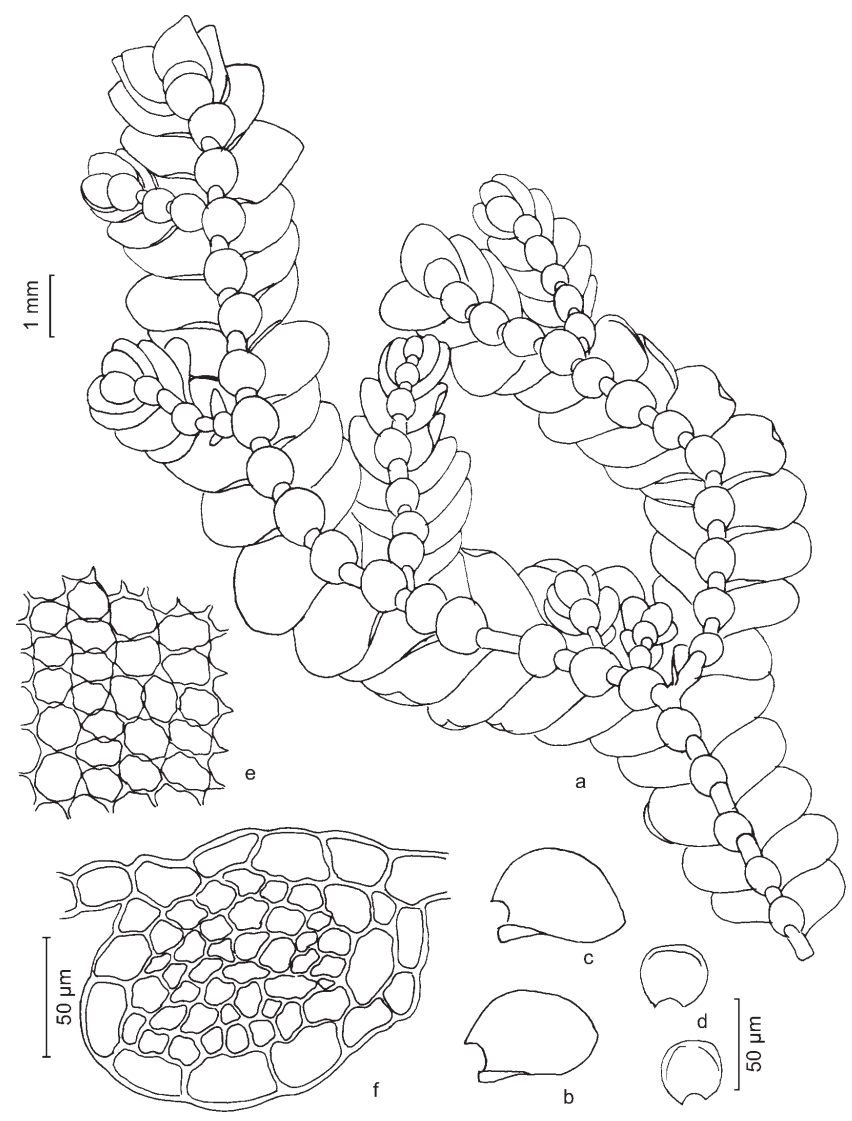

Figura 7. Acanthocoleus trigonus. a. aspecto geral do gametófito, vista ventral. b, c. lobo do filídio. d. anfigastro. e. células do lobo do filídio com trigônios. f. secção transversal do caulídio (O. Yano \& J. Bordin 29232, SP385697).

Figure 7. Acanthocoleus trigonus. a. habit of gametophyte, ventral view. b, c. leaf lobe. d. underleaf. e. cells of leaf lobe with trigones. f. cross section of stem $(O$. Yano \& J. Bordin 29232, SP385697).

sobre tronco de Araucaria, 17-XII-2005, J. Bordin \& D.F. Peralta 184p.p. (HUCS27206, SP379854); idem, beira da mata, tronco de Cupressus, 18-VI-2006, J. Bordin, M.A. Bordin \& A. Benedetti 519 (HUCS28586, SP383074); Jardim Botânico de Caxias do Sul, nos galhos das árvores, 6-X-2006, O. Yano \& J. Bordin 29243 (SP385708).

Distribuição no Brasil: AC, AL, AM, BA, ES, GO, MA, MG, MS, MT, PA, PR, RJ, RO, RR e SP.

Comentários: reconhecida pelos ramos filiformes, filídios com lobos ovalado-orbiculares, levemente falcados, lóbulos inflados, com 5-7 dentes de 1-2 células na margem e anfigastros inteiros, ovalados a obovados, imbricados.

Ocorre geralmente sobre troncos de árvores isoladas ou em matas úmidas (Yano \& Costa 1992), em ambientes relativamente secos e abertos, em restingas e florestas 


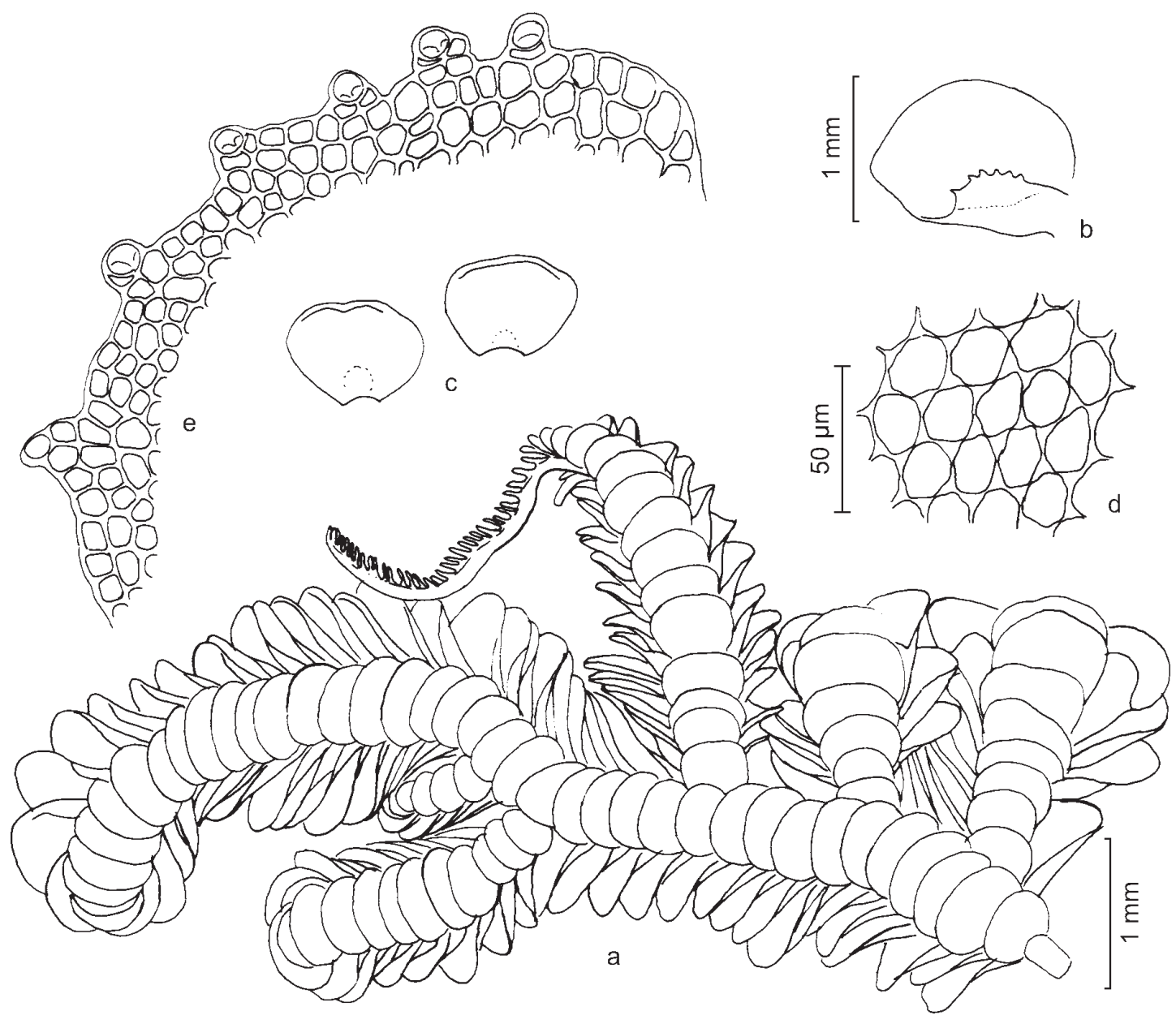

Figura 8. Acrolejeunea torulosa. a. Aspecto geral do gametófito, vista ventral. b. Lobo e lóbulo do filídio. c. Anfigastros. d. Células do lobo do filí́dio. e. Dentes da margem do lóbulo (D.M. Vital 3009, SP88447).

Figure 8. Acrolejeunea torulosa. a. Habit of gametophyte, ventral view. b. Lobe and leaf lobule. c. Underleaves. d. Cells of leaf lobe. e. Marginal teeth of lobe (D.M. Vital 3009, SP88447).

decíduas, raramente sobre rochas, até $800 \mathrm{~m}$ de altitude (Gradstein \& Costa 2003). É a espécie mais comum de Acrolejeunea nos neotrópicos (Gradstein 1994). Foi coletada em matas ou beira de matas, sobre troncos e base de troncos, associada com Frullania brasiliensis Raddi, F. montagnei Gottsche, Groutiella apiculata (Hook.) H.A. Crum \& Steere e Macrocoma orthotrichoides (Raddi) Wijk \& Margad.

A espécie foi citada para o Paraná por Schiffner \& Arnell (1964) e possui uma ampla distribuição no Brasil, tendo sua ocorrência esperada para o Rio Grande do Sul.

Archilejeunea parviflora (Nees) Schiffn., Spec. Hepat. 4:716. 1911. 三 Jungermannia parviflora Nees in Martius, Flora Brasil. enum. plant. 1:353. 1833. Figura 9
Material examinado: BRASIL. Rio GRANDE do SUL: Caxias do Sul, Centro, Rua Pinheiro Machado, sobre tronco de Ligustrum, 12-XI-2005, J. Bordin 159p.p. (HUCS27255, SP379477).

Distribuição no Brasil: AC, AM, AP, BA, ES, MS, MT, PA, PE, RJ, RO, RR, SC e SP.

Comentários: reconhecida pelos lobos orbiculares a ovalados dos filídios com ápice curvado para o lado ventral, lóbulos reduzidos e anfigastros pequenos, orbiculares, com ápice truncado a arredondado, contíguos a distantes.

A espécie é comum em base de troncos, raízes e rochas, em hábitats periodicamente inundados, ao longo de riachos ou rios, em florestas tropicais, úmidas e submontanas, em toda a América Tropical, do nível do mar até $1.500 \mathrm{~m}$ de altitude (Gradstein 1994). No Brasil está bem distribuída em todas as regiões, sendo esperada para 


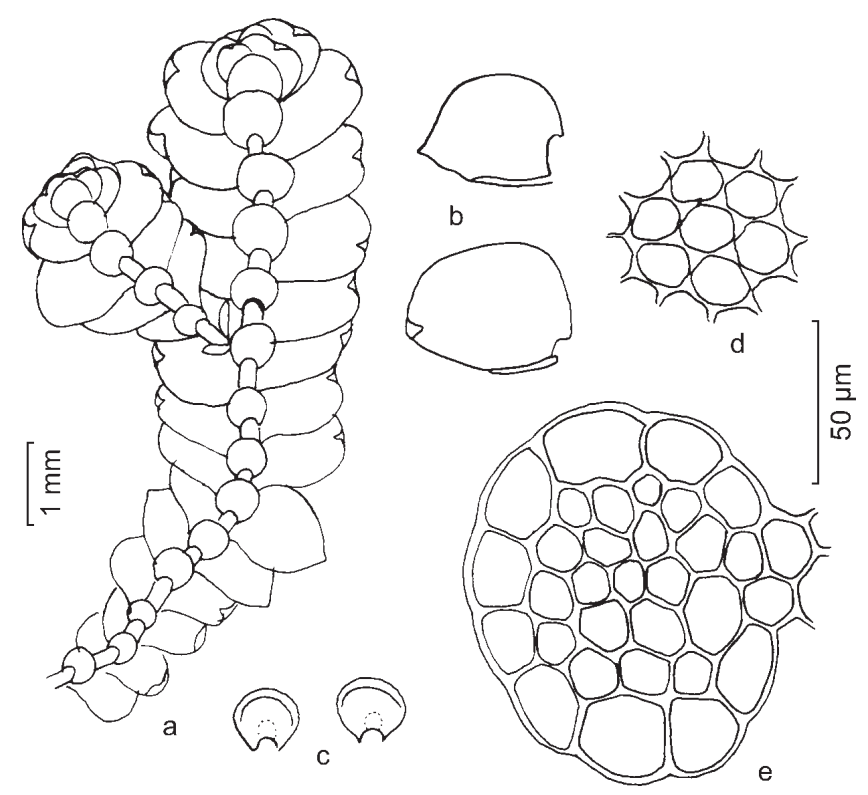

Figura 9. Archilejeunea parviflora. a. Aspecto geral do gametófito, vista ventral. b. Lobos do filídio. c. Anfigastros. d. Células do lobo do filídio. e. Secção transversal do caulídio (J. Bordin 159p.p., SP379477).

Figure 9. Archilejeunea parviflora. a. Habit of gametophyte, ventral view. b. Lobes of leaf. c. Underleaves. d. Cells of leaf lobe. e. Cross section of stem (J. Bordin 159p.p., SP379477).

o Rio Grande do Sul, onde foi coletada sobre troncos, em ruas arborizadas, associada com Colobodontium vulpinum (Mont.) S.P. Churchill \& W.R. Buck.

Drepanolejeunea anoplantha (Spruce) Steph., Spec. Hepat. 5:325. 1913. ELejeunea anoplantha Spruce, Trans. \& Proc. Bot. Soc. Edinburgh 15:189. 1884.

Figura 10

Material examinado: BRASIL. Rio GRANDE Do SUL: Caxias do Sul, Parque dos Macaquinhos, sobre tronco de Lauraceae, 6-X-2006, O. Yano \& J. Bordin 29220p.p. (HUCS29578, SP385685); Universidade de Caxias do Sul, Mata do Museu, sobre tronco, 4-X-2006, O. Yano \& J. Bordin 29155 (HUCS29555, SP385533).

Distribuição no Brasil: AM, BA, CE, ES e SP.

Comentários: reconhecida pelos gametófitos delicados, filídios contíguos a distantes, com lobos triangulares e ápice agudo, 2 ocelos na base do lobo e pelos lóbulos inflados, cobrindo metade do lobo, com dente longo e papila hialina.

Ocorre sobre cascas de árvore, até $2000 \mathrm{~m}$ de altitude (Gradstein \& Costa 2003). Foi coletada sobre troncos, em parques e na mata, associada com Microlejeunea globosa (Spruce) Steph.

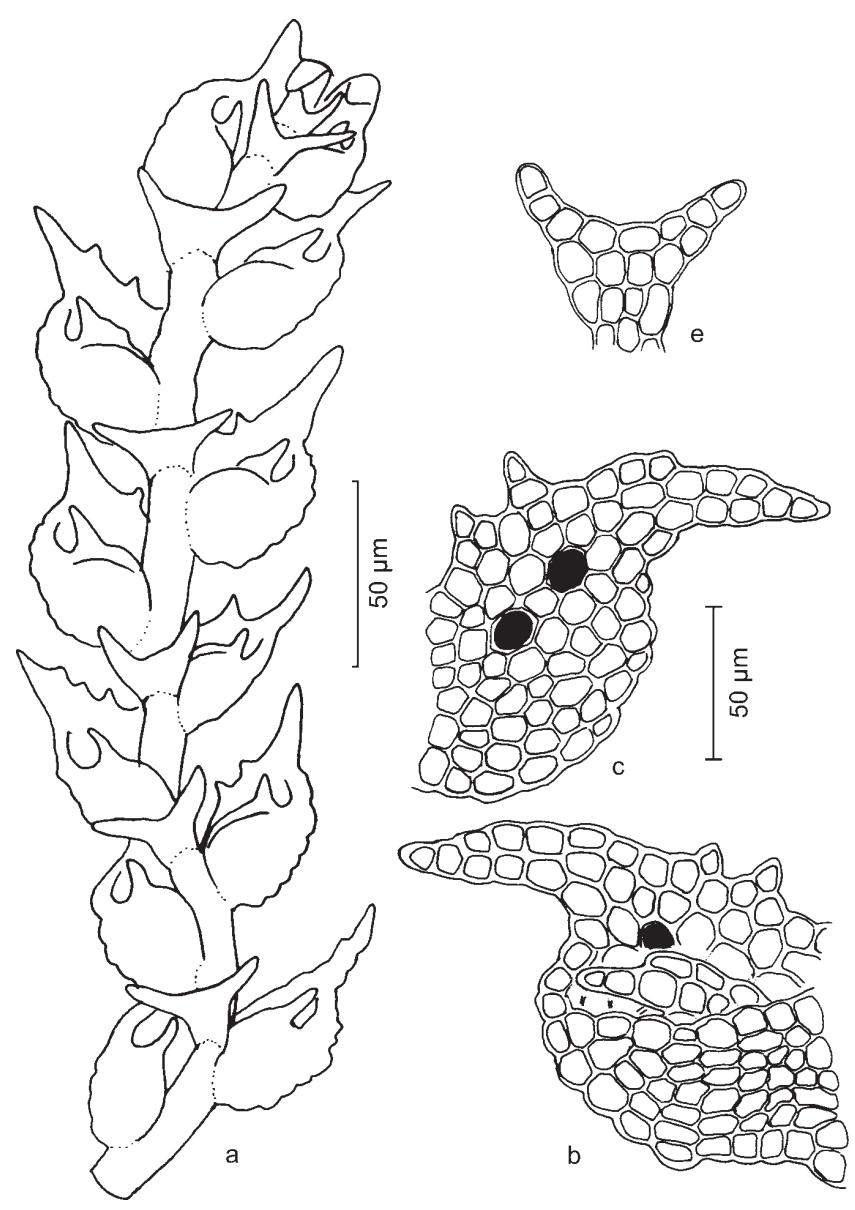

Figura 10. Drepanolejeunea anoplantha. a. Aspecto geral do gametófito. b. Lobo e lóbulo do filídio. c. Lobo do filídio em vista dorsal mostrando ocelos. d. Anfigastro (O. Yano \& J. Bordin 29220p.p., SP385685).

Figure 10. Drepanolejeunea anoplantha. a. Habit of gametophyte. b. Lobe and leaf lobule. c. Leaf lobe with ocelli, dorsal view. d. Underleaf (O. Yano \& J. Bordin 29220p.p., SP385685).

Esta é a primeira ocorrência da espécie na região Sul do Brasil, ampliando assim sua distribuição geográfica no país.

Lejeunea cancellata Nees \& Mont. in Ramón de la Sagra, Hist. Phys. Bot. Plant. Cell. Cuba 9:472. 1842. Figura 11

Material examinado: BRASIL. Rio GRANDE Do SUL: Caxias do Sul, Universidade de Caxias do Sul, sobre rocha úmida perto do Biolago, 4-X-2006, O. Yano \& J. Bordin 29163 (SP385541); Jardim Botânico de Caxias do Sul, sobre tronco de arbusto na beira do riacho, 6-X2006, O. Yano \& J. Bordin 29245 (HUCS29592, SP385710). 
Distribuição no Brasil: AL, BA, CE, ES, GO, MS, MT, RJ, RS (Caxias do Sul, Travessão Gablontz), SC e SP.

Comentários: reconhecida pelos filídios com lobos ovalados, ápice arredondado ou agudo, às vezes curvado para o lado ventral, lóbulos côncavos, com dente apical e anfigastros bífidos, distantes.

O ápice do lóbulo é muito variável, de arredondado até mais ou menos agudo. Encontra-se geralmente sobre casca de árvore (Reiner-Drehwald 2000). Foi coletada sobre rocha e tronco, em lugares úmidos.

Esta é a segunda referência da espécie para o Rio Grande do Sul. Peralta et al. (2008), citaram este táxon para uma área de Floresta Ombrófila Mista, no interior do município de Caxias do Sul. Esta nova coleta, na área urbana, amplia a distribuição geográfica deste táxon, confirmando que o mesmo é bastante comum, porém pouco coletado.

Lejeunea cardotii Steph., Bot. Gaz., Crawfordswille 7: 356. 1882.

Figura 12

Material examinado: BRASIL. RIo GRANDE do SUL: Caxias do Sul, Parque Cinqüentenário, base do tronco de Araucaria angustifolia, 3-X-2006, O. Yano \& J. Bordin 29060 (SP385438).

Distribuição no Brasil: MS, PR e SP.

Comentários: reconhecida pelos filídios com lobos arredondados cobertos parcialmente pelos lóbulos ovóides, com dente apical pequeno e pelos anfigastros distantes,
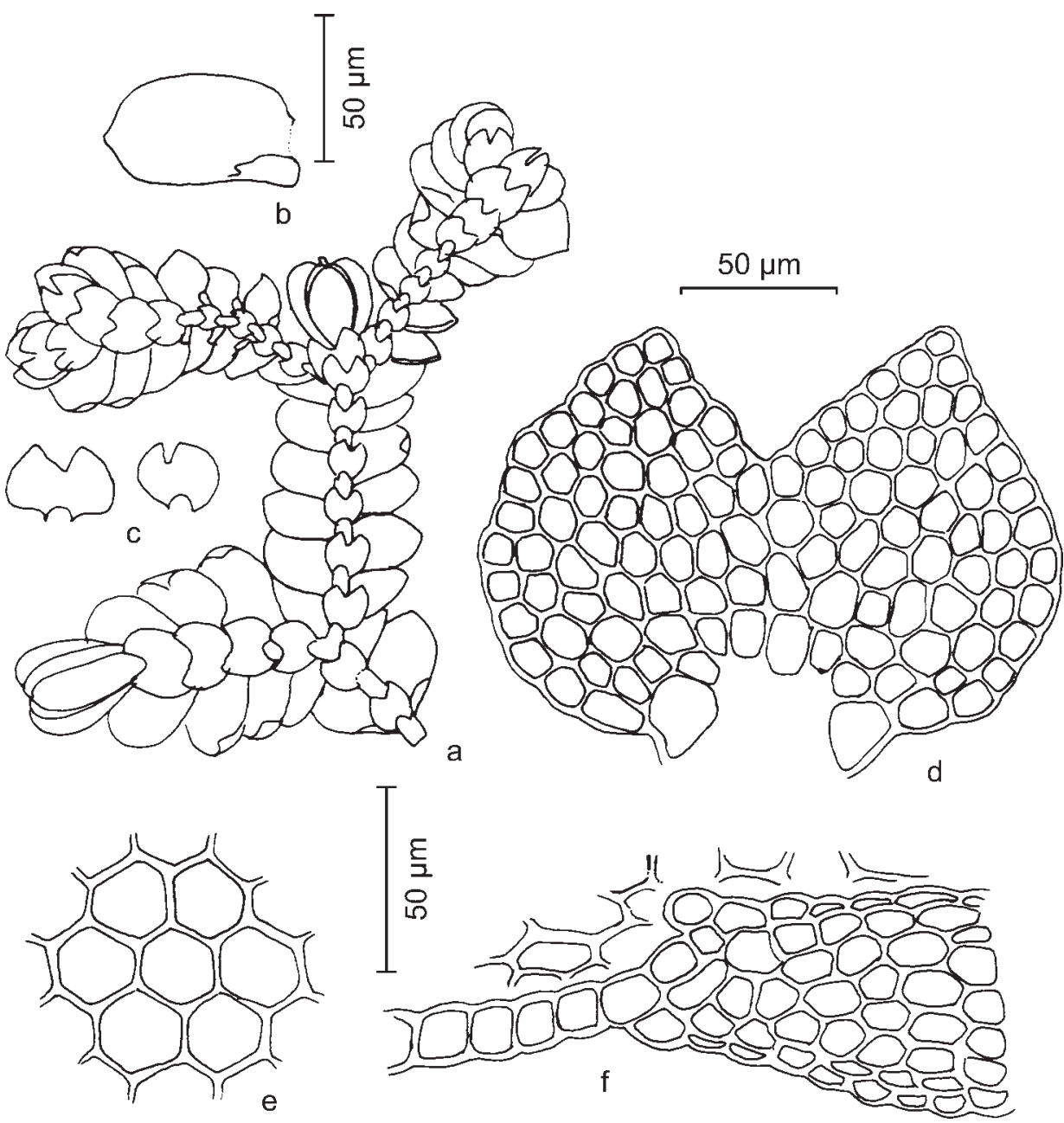

Figura 11. Lejeunea cancellata. a. Aspecto geral do gametófito, vista ventral. b. Lobo do filídio. c. Anfigastros. d. Células do anfigastro. e. Células do lobo do filídio. f. Lóbulo do filídio (O. Yano \& J. Bordin 29163, SP385541).

Figure 11. Lejeunea cancellata. a. Habit of gametophyte, ventral view. b. Leaf lobe. c. Underleaves. d. Cells of underleaf. e. Cells of leaf lobe. f. Leaf lobule (O. Yano \& J. Bordin 29163, SP385541). 


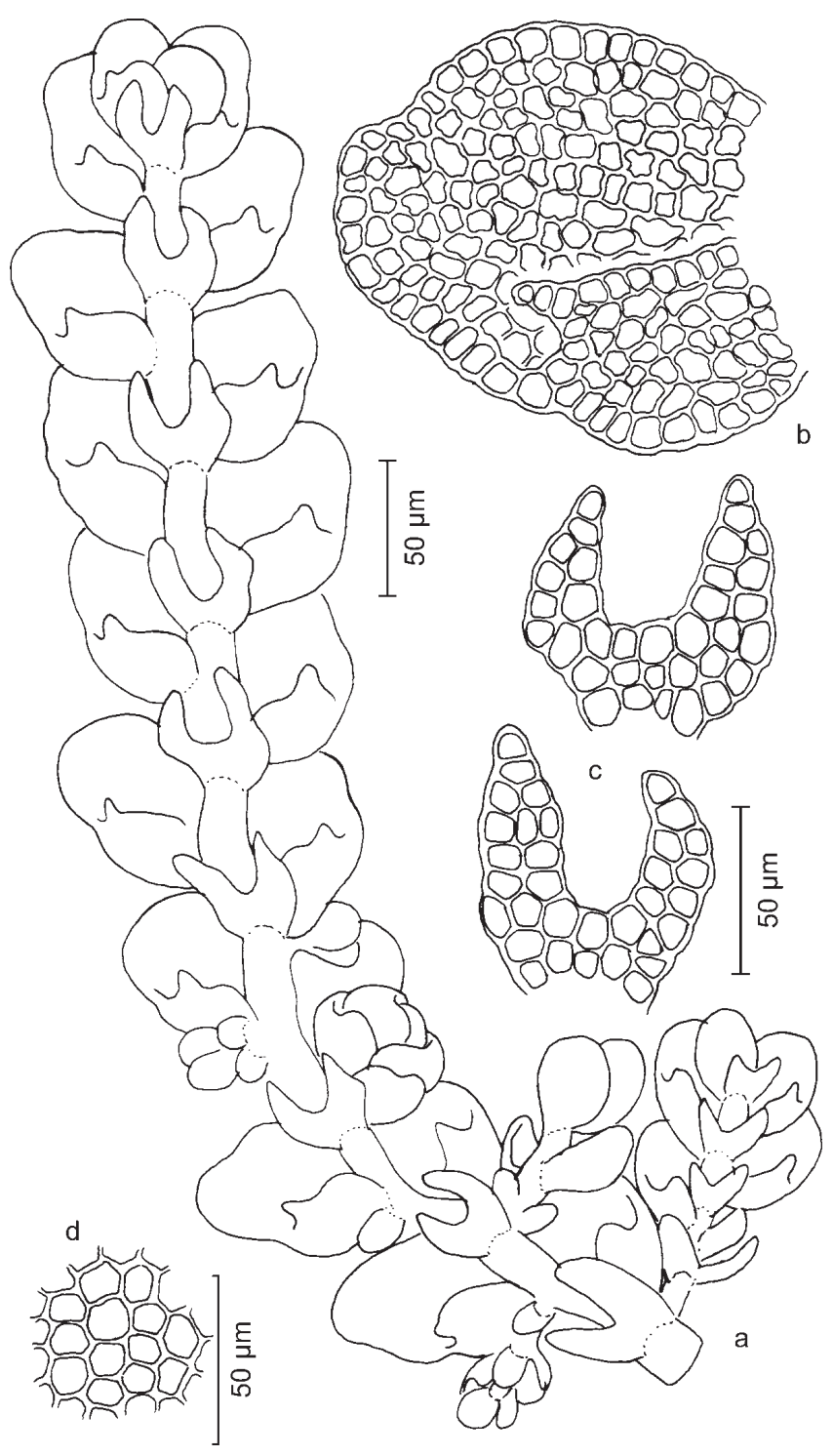

Figura 12. Lejeunea cardotii. a. Aspecto geral do gametófito. b. Lobo e lóbulo do filídio. c. Anfigastros. d. Células do lobo do filídio (O. Yano \& J. Bordin 29060, SP385438).

Figure 12. Lejeunea cardotii. a. Habit of gametophyte. b. Lobe and leaf lobule. c. Underleaves. d. Cells of leaf lobe (O. Yano \& J. Bordin 29060, SP385438).

bífidos, oval-oblongos, com 2-3(-4) células na base e 2(-3) superpostas no ápice.

Ocorre em troncos, ramos e bases de árvores sendo considerada tolerante a ambientes perturbados e áreas urbanas (Schuster 1980).

No Brasil, possui uma distribuição restrita, ocorrendo somente em três Estados. Foi citada para o Paraná por Schäfer Verwimp \& Giancotti (1993) e esta nova citação para o Rio Grande do Sul, amplia sua distribuição geográfica.
Lejeunea cristulata (Steph.) E. Reiner \& Goda, J. Hattori Bot. Lab. 89:19. 2000. $\equiv$ Crossotolejeunea cristulata Steph., Hedwigia 35:75. 1896.

Figura 13

Material examinado: BRASIL. RIO GRANDE DO Sul: Caxias do Sul, Universidade de Caxias do Sul, Mata em frente ao MUCS, sobre tronco de Cupania vernalis, 22-XII-2005, J. Bordin et al. 188p.p. (HUCS27281, SP379703); Jardim Botânico de Caxias do Sul, interior da mata, sobre tronco, 12-I-2006, J. Bordin, R. Wasum \& M. Sartori 268p.p. (HUCS27385, SP379717).

Distribuição no Brasil: MG, PE, RJ, SC e SP.

Comentários: reconhecida pelos gametófitos delgados, lobos ovalados com lóbulos inflados, côncavos e anfigastros distantes, pequenos, curtos, mais largos do que longos.

Em gametófitos com lóbulos reduzidos, estes são normalmente curvados para o lado dorsal, enquanto que os filídios com lóbulos desenvolvidos são mais ou menos côncavos para o lado ventral (Reiner-Drehwald \& Goda 2000).

Cresce sobre troncos ou epífila em florestas úmidas, entre 900-1.500 m de altitude (Reiner-Drehwald \& Goda 2000). Foi coletada no interior da mata, sobre troncos, associada a Leucolejeunea unciloba (Lindenb.) A. Evans, Neckera villae-ricae Besch., Thuidium delicatulum (Hedw.) Bruch \& Schimp. e Radula tectiloba Steph.

É uma espécie com ocorrência restrita ao Brasil (Yano 2008), ocorrendo de maneira disjunta em diversos Estados.

Lejeunea glaucescens Gottsche, Syn. Hepat.: 378. 1845. Figura 14

Material examinado: BRASIL. Rio GRANDE Do Sul: Caxias do Sul, Parque Cinqüentenário, sobre tronco, 3-X-1006, O. Yano \& J. Bordin 29051p.p. (SP383812); Jardim Botânico de Caxias do Sul, sobre troncos em decomposição, 18-IV-2006, J. Bordin et al. 502p.p., (HUCS28095, SP383004).

Distribuição no Brasil: AC, BA, CE, DF, ES, MS, MT, PE, PR, RJ, RR, SC e SP.

Comentários: reconhecida pelos lobos dos filídios arredondados, lóbulo com dente apical pouco visível e anfigastros bífidos, suborbiculares a ovalados.

A espécie é comum nos troncos de árvores em florestas tropicais, até $1.100 \mathrm{~m}$ de altitude (Gradstein \& Costa 2003). Foi coletada sobre troncos de árvores e troncos em decomposição em parques e na mata, associada 


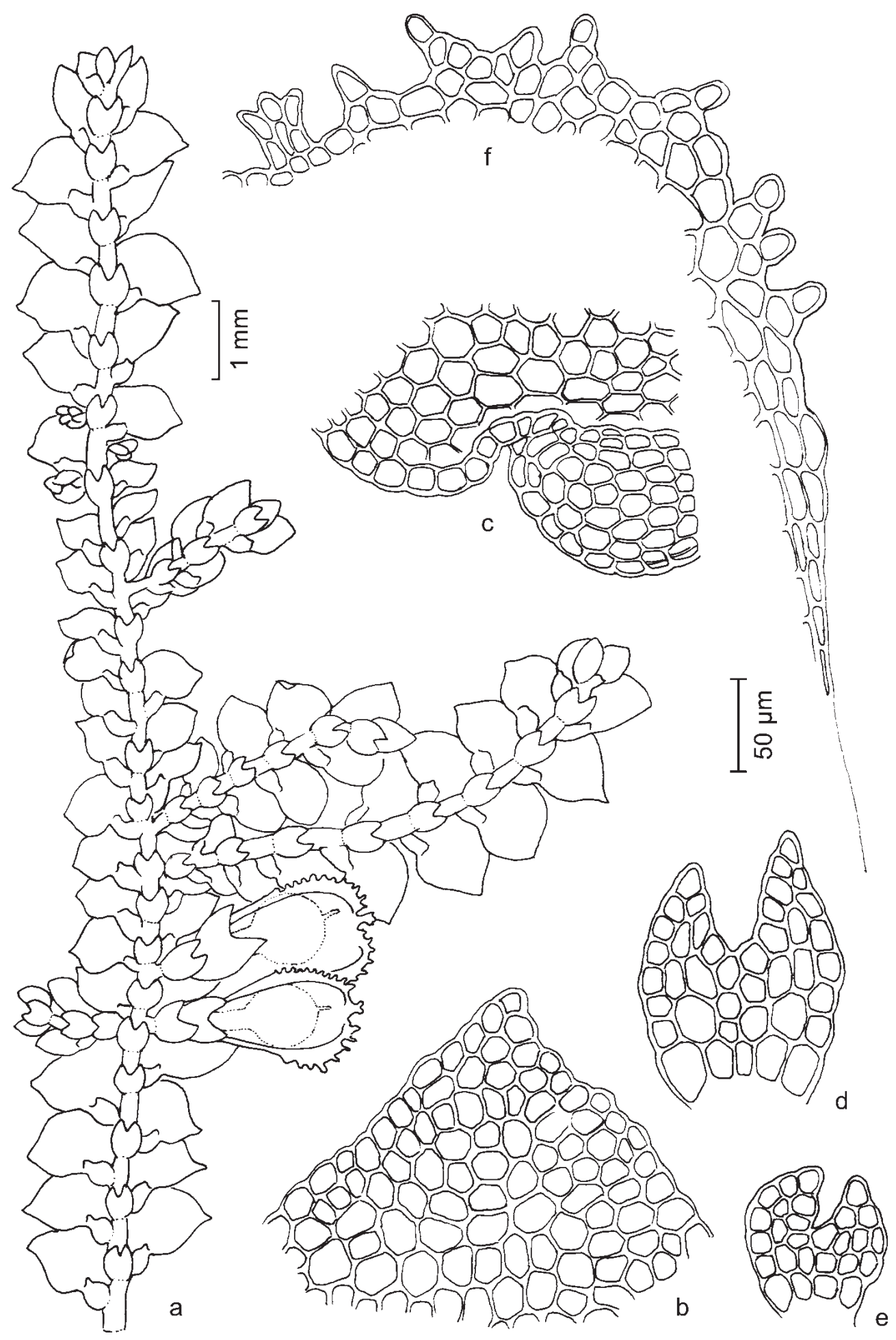

Figura 13. Lejeunea cristulata. a. Aspecto geral do gametófito. b. Ápice do lobo do filídio. c. Lóbulo do filídio. d, e. Anfigastros. f. Células da margem do perianto (Schäfer-Verwimp 7620, SP386116).

Figure 13. Lejeunea cristulata. a. Habit of gametophyte. b. Lobe apex. c. Leaf lobule. d, e. Underleaves. f. Marginal cells of perianth (Schäfer-Verwimp 7620, SP386116). 

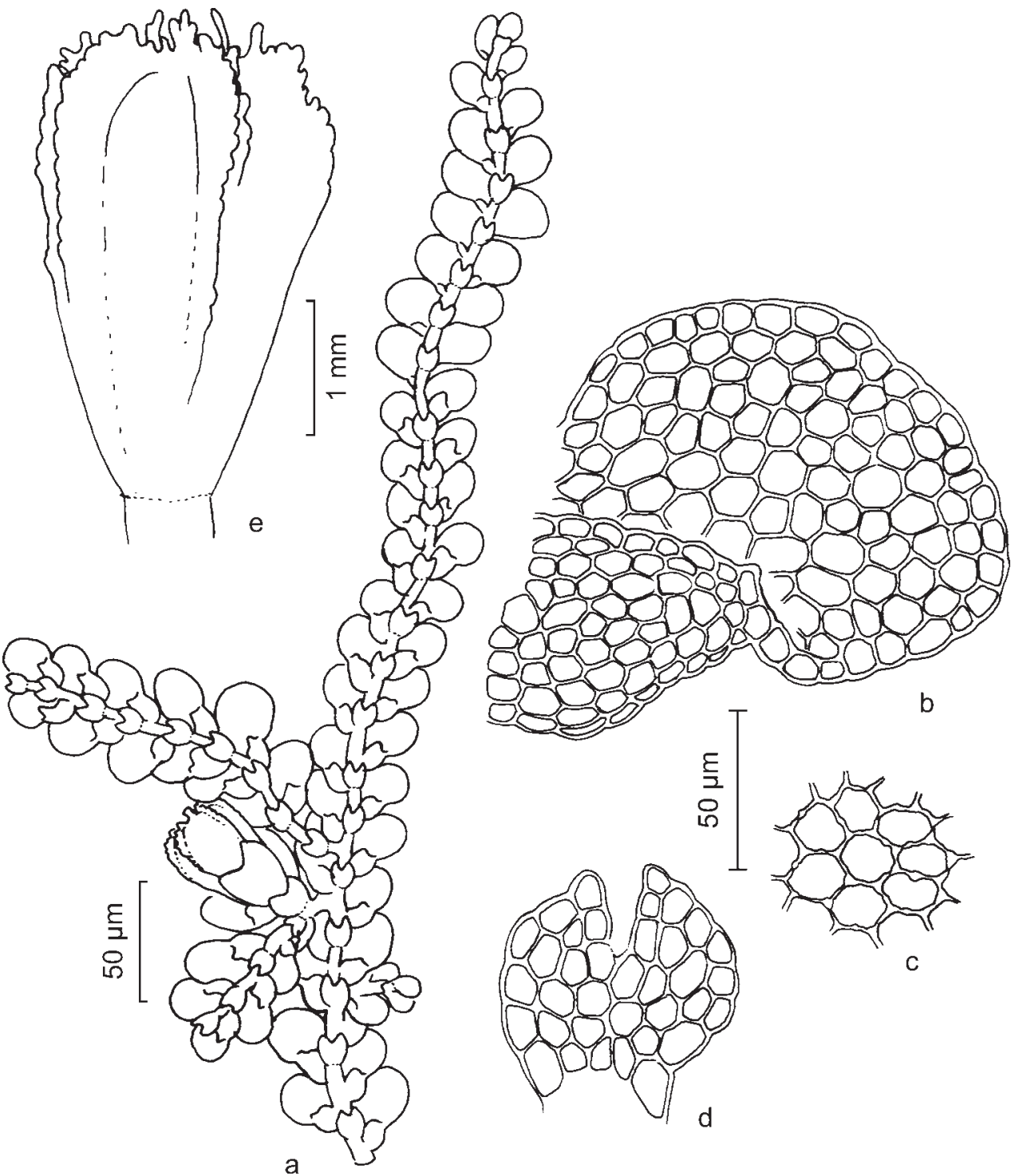

Figure 14. Lejeunea glaucescens. a. Aspecto geral do gametófito. b. Lobo e lóbulo do filídio. c. Células do lobo do filídio. d. Anfigastro. e. Perianto (J. Bordin et al. 502p.p., SP383004).

Figure 14. Lejeunea glaucescens. a. Habit of gametophyte. b. Lobe and lobule of leaf. c. Cells of leaf lobe. d. Underleaf. e. Perianth (J. Bordin et al. 502p.p., SP383004).

com Lejeunea laetevirens Nees \& Mont., Lophocolea muricata (Lehm.) Nees. e Sematophyllum galipense (Müll. Hal.) Mitt.

Esta nova citação para o Rio Grande do Sul cobre uma importante lacuna na distribuição geográfica da espécie, uma vez que a mesma já havia sido citada para o Paraná e Santa Catarina.

Lejeunea laetevirens Nees \& Mont. in Ramón de la Sagra, Hist. Phys. Bot. Plant. Cell. Cuba 9:469. 1842. Figura 15
Material examinado: BRASIL. Rio GRANDE do SUL: Caxias do Sul, Parque Cinqüentenário, sobre tronco, 3-X-2006, O. Yano \& J. Bordin 29051p.p. (SP383812); Universidade de Caxias do Sul, na Mata do Museu, sobre tronco de Sloanea, 22-XII-2005, J. Bordin et al. 190, 191p.p. (HUCS27278, SP379484; HUCS27284, SP379489); idem, interior da Mata da Capela, sobre tronco de Nectandra, 3-XII-2005, J. Bordin \& L. Bordin 176p.p. (HUCS27194, SP379700); idem, Mata do Museu, sobre tronco, O. Yano \& J. Bordin 29153p.p. (HUCS29554, SP385531); Jardim Botânico de Caxias 


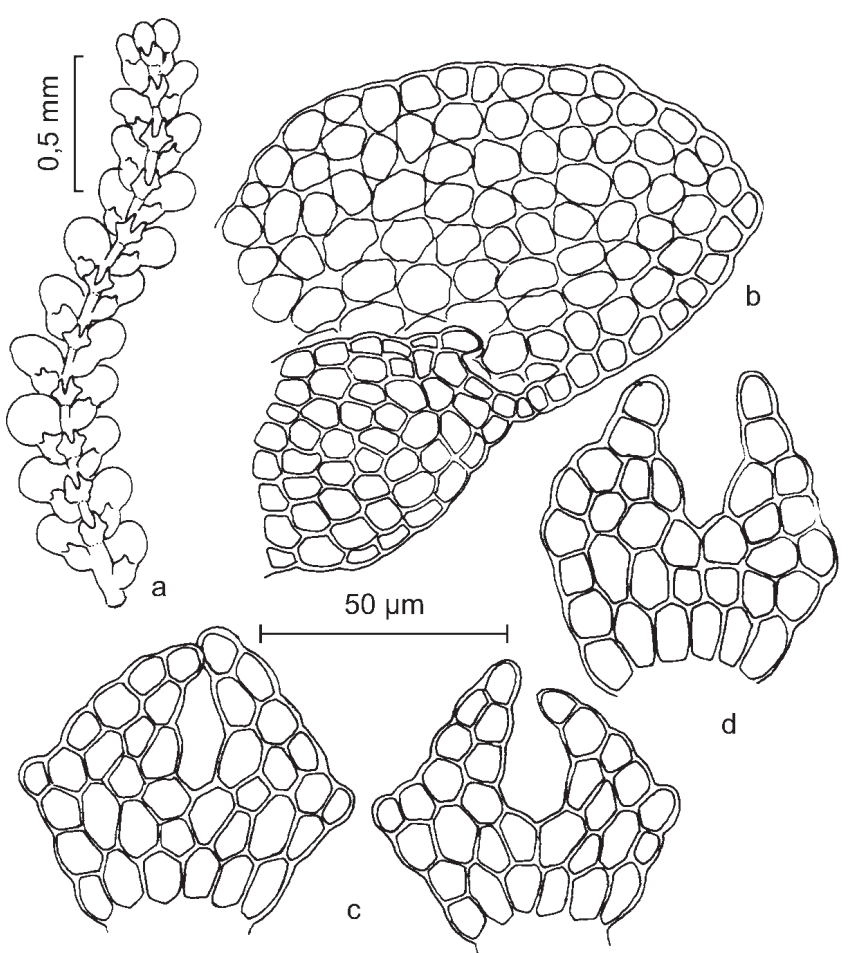

Figura 15. Lejeunea laetevirens Nees \& Mont. a. Aspecto geral do gametófito, vista ventral. b. Lobo e lóbulo do filídio. c, d. Anfigastros (O. Yano et al. 14306, SP229502).

Figure 15. Lejeunea laetevirens Nees \& Mont. a. Habit of gametophyte, ventral view. b. Lobe and lobule of leaf. c, d. Underleaves (O. Yano et al. 14306, SP229502).

do Sul, na mata, sobre tronco, 12-IV-2006, J. Bordin, E. Pasini \& T. Ziembowicz 445p.p. (HUCS28042, SP382977); idem, orla da mata, sobre troncos, 12-IV-2006, J. Bordin, E. Pasini \& T. Ziembowicz 435a p.p. (HUCS28059, SP382988); idem, na mata, sobre troncos, 12-IV-2005, J. Bordin, E. Pasini \& T. Ziembowicz 455 (HUCS28057, SP382986); idem, na mata de Pinus, sobre troncos, 12-IV-2005, J. Bordin, E. Pasini \& T. Ziembowicz 437p.p. (HUCS28149, SP383019); idem, O. Yano \& J. Bordin 29191 (HUCS29542, SP385569).

Distribuição no Brasil: AC, AL, AM, AP, BA, CE, DF, ES, FN, GO, MG, MS, MT, PA, PB, PE, RJ, RR, SC, SE e SP.

Comentários: reconhecida pelos gametófitos delicados, verde-amarelados a verde-claros, emaranhados, com filídios distantes, células diferenciadas na margem do lobo, menores e arredondadas e anfigastros trapezoidais, com dente lateral bem distinto.

No material examinado foram observadas grandes variações no lóbulo e anfigastros e conforme ReinerDrehwald (2000), quando o lóbulo é reduzido, com um dente de (1-)2 células, os anfigastros possuem margem irregular, com dentes laterais grandes. Já os lóbulos desenvolvidos estão associados a anfigastros com margem inteira.

Geralmente cresce sobre cascas de árvore, ramos e troncos podres e sobre rochas (Reiner-Drehwald 2000). Também ocorre em florestas tropicais, matas, cerrado, restinga, plantações, parques e árvores isoladas (Gradstein \& Costa 2003). Bastos (2004) encontrou a espécie na zona urbana de Salvador (Bahia), epifitando árvores de praças e avenidas. Está bem distribuída em quase todos os Estados brasileiros. Ocorre em Santa Catarina e era esperada para o Rio Grande do Sul, onde foi coletada sobre troncos em parques e na mata, associada com $L$. glaucescens Gottsche, L. phyllobola Nees \& Mont., Metzgeria fruticola Spruce, M. furcata (L.) Dumort., Radula tectiloba Steph. e Thuidium tomentosum Besch.

Lejeunea setiloba Spruce, Trans. \& Proc. Bot. Soc. Edinburgh 15:281. 1884.

Figura 16

Material examinado: BRASIL. RIo GRANDE Do SUL: Caxias do Sul, Parque Cinqüentenário, sobre tronco de Sloanea, 30-XII-2005, J. Bordin \& L. Brancher 227p.p. (HUCS27356, SP379881); idem, sobre tronco, 3-X-2006, O. Yano \& J. Bordin 29052 (HUCS29471, SP383813); Universidade de Caxias do Sul, na mata, sobre tronco de Sloanea, 3-XII-2005, J. Bordin \& L. Bordin 174p.p. (HUCS27193, SP379849); Jardim Botânico de Caxias do Sul, interior da mata, sobre troncos, 18-IV-2006, J. Bordin et al. 504p.p. (HUCS28146, SP383023).

Distribuição no Brasil: AM, CE, MS e SP.

Comentários: reconhecida pelos filídios arredondados, lóbulos variáveis, reduzidos, podendo apresentar base retangular e dente apical longo, filiforme de (2-) 3-4 (-6) células de altura ou base triangular e dente de 1-3 células de altura, anfigastros pequenos, distantes a contíguos.

Cresce sobre a base de troncos e raízes de árvores grandes, sobre troncos e ramos caídos, em decomposição, sobre rochas e raramente sobre o solo (Reiner-Drehwald 2000), até $1.100 \mathrm{~m}$ de altitude (Gradstein \& Costa 2003). Foi coleada sobre troncos, em parques e na mata, associada com Lejeunea flava (Sw.) Nees, Metzgeria furcata (L.) Dumort., Orthostichella rigida (Müll. Hal.) B.H. Allen \& Magill e Radula nudicaulis Steph.

A espécie possui uma distribuição restrita no Brasil, ocorrendo em apenas quatro Estados. É a primeira referência para a região Sul e isto amplia significativamente sua distribuição geográfica, indicando que a mesma pode também ocorrer nos demais Estados desta região. 


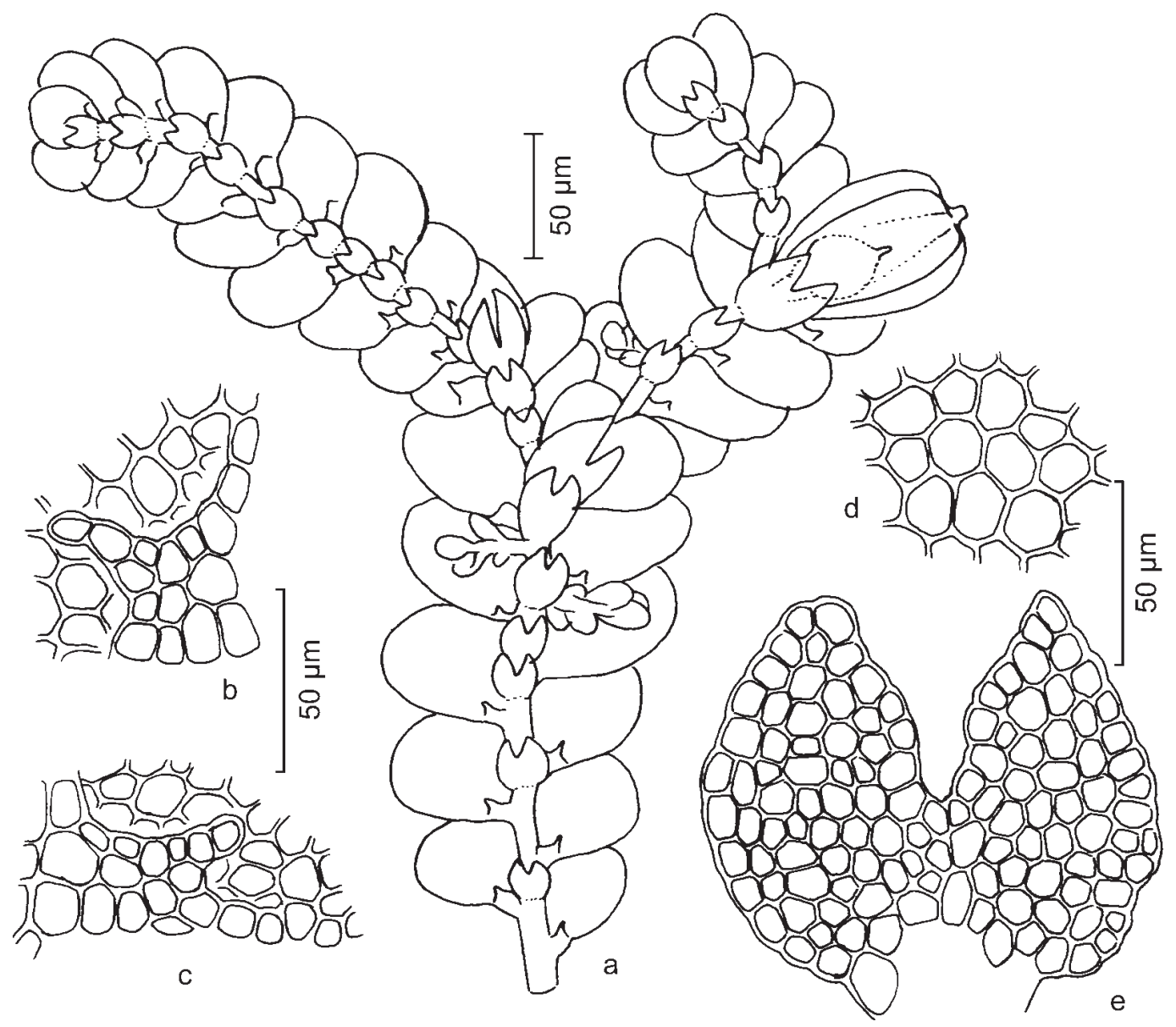

Figura 16. Lejeunea setiloba. a. Aspecto geral do gametófito, vista ventral. b, c. Lóbulo do filídio. d. Células do lobo do filídio. e. Anfigastro (O. Yano \& J. Bordin 29052, SP383813).

Figure 16. Lejeunea setiloba. a. Habit of gametophyte, ventral view. b, c. Leaf lobule. d. Cells of leaf lobe. e. Underleaf $(O$. Yano \& J. Bordin 29052, SP383813).

Lopholejeunea nigricans (Lindenb.) Schiffn., Consp. Hepat. Archip. Ind.: 293. 1898. $\equiv$ Lejeunea nigricans Lindenb. in Gottsche et al., Syn. Hepat.: 316. 1845. Figura 17

Material examinado: BRASIL. RIo GRANDE Do SUL: Caxias do Sul, Centro, sobre tronco de Ligustrum, 12XI-2005, J. Bordin 158p.p. (HUCS27163, SP379697).

Distribuição no Brasil: AC, AM, BA, CE, DF, ES, GO, MG, MS, MT, PA, PE, PR, RJ, SC e SP.

Comentários: reconhecida pelo gametófito de coloração verde-escura com partes enegrecidas, filídios com ápice agudo-apiculado, curvado para o lado ventral e pelos anfigastros distantes, inteiros, arredondados.

A espécie distribui-se bem em todas as regiões brasileiras e já foi citada para os Estados do Paraná e Santa Catarina sendo, portanto, esperada para o Rio Grande do Sul. Neste Estado, foi encontrada em floresta ombrófila, crescendo como corticícola e epixícola (Bastos \& Yano 2006). Também ocorre sobre rochas em florestas, até $1.000 \mathrm{~m}$ de altitude (Gradstein \& Costa 2003). Foi coletada em área antropizada, sobre tronco, associada com Brachymenium hornschuchianum Mart. e Colobodontium vulpinum (Mont.) S. P. Churchill \& W. R. Buck.

Microlejeunea bullata (Taylor) Steph., Hedwigia 29:90. 1890. Lejeunea bullata Taylor, London J. Bot. 5:398. 1846.

Figura 18

Material examinado: BRASIL. Rio GRANDE do SUL: Caxias do Sul, Universidade de Caxias do Sul, Mata da Biblioteca, sobre troncos, 4-X-2006, O. Yano \& J. Bordin 29160 (SP385538); Jardim Botânico de Caxias do Sul, na mata, sobre tronco de Schinus, 18-IV-2006, J. Bordin 


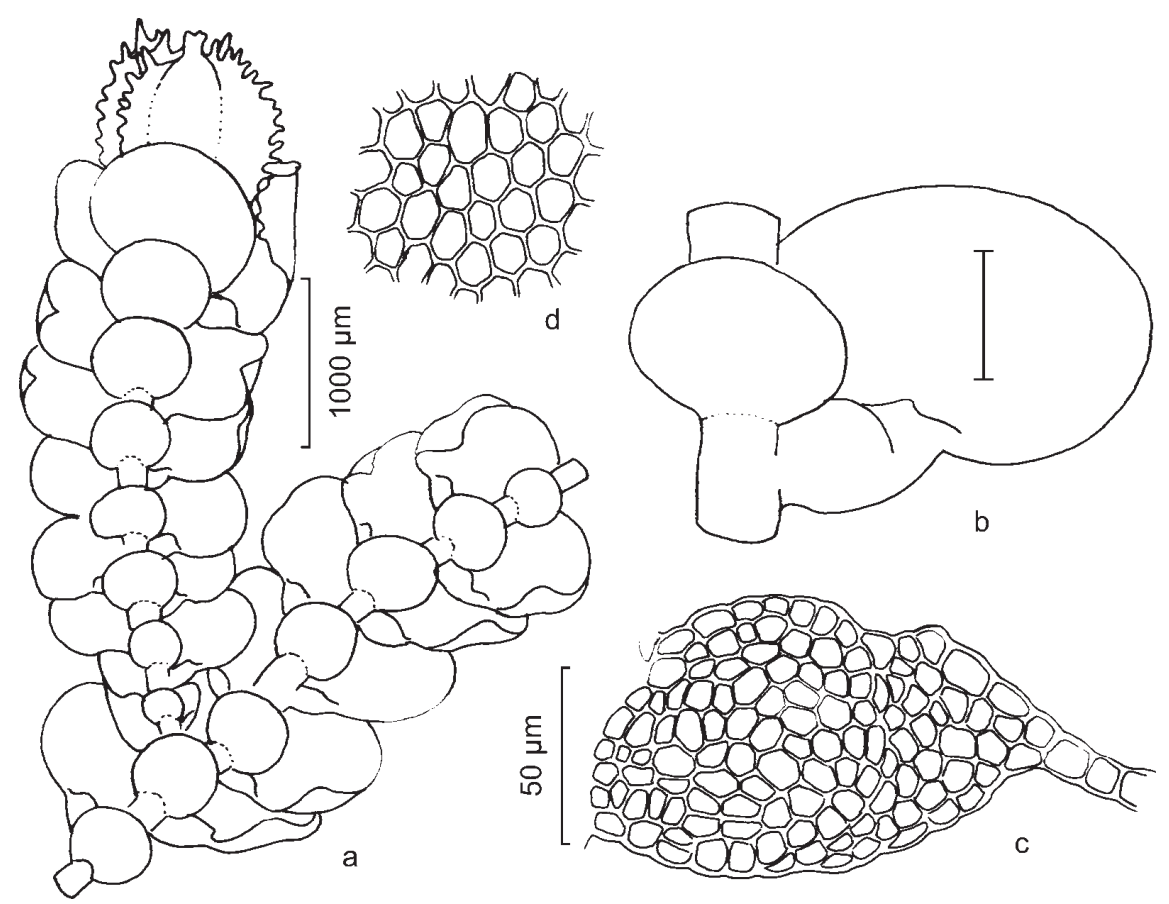

Figura 17. Lopholejeunea nigricans. a. Aspecto geral do gametófito, vista ventral. b. Lobo do filídio. c. Lóbulo do filídio. d. Células do lobo do filí́dio (O. Yano 1370, SP134012).

Figure 17. Lopholejeunea nigricans. a. Habit of gametophyte, ventral view. b. Lobe and lobule of leaf. c. Leaf lobule. d. Cells of leaf lobe (O. Yano 1370, SP134012).

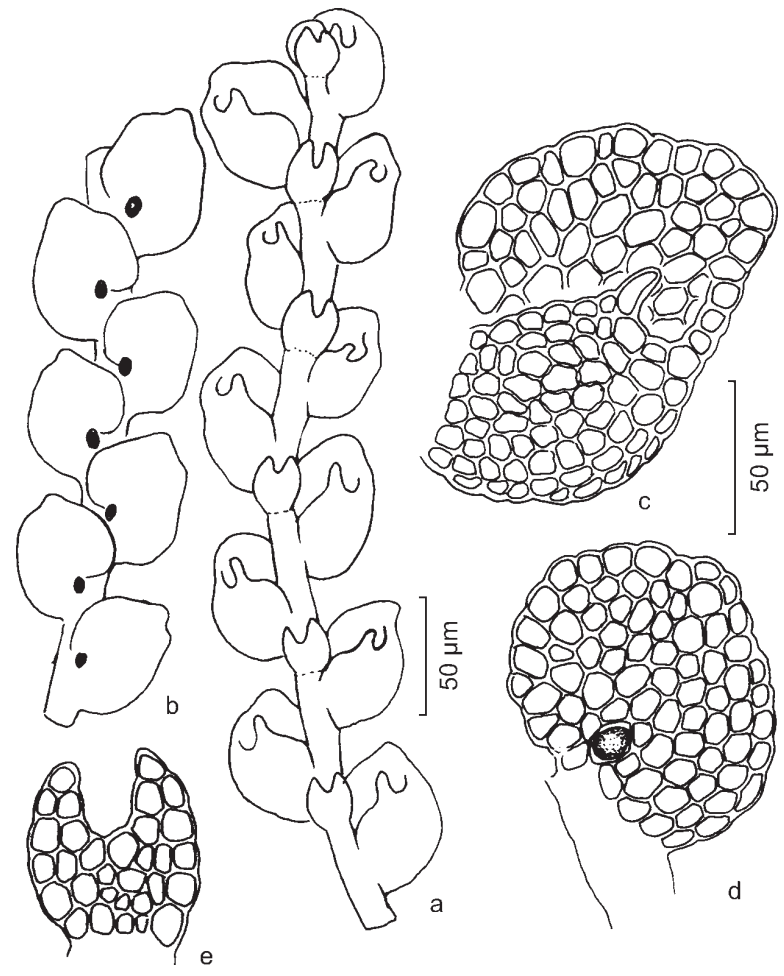

Figura 18. Microlejeunea bullata. a. Aspecto geral do gametófito, vista ventral. b. Aspecto geral do gametófito, vista dorsal. c. Lobo e lóbulo do filídio. d. Lobo em vista dorsal mostrando ocelo. e. Anfigastro (O. Yano \& J. Bordin 29160, SP385538). et al. 494p.p. (HUCS28022, SP379927); Jardim Botânico de Caxias do Sul, sobre tronco de arbusto na beira do riacho, 6-X-2006, O. Yano \& J. Bordin 29244p.p. 29259p.p. (HUCS29591, SP385709; HUCS29603, SP385724).

Distribuição no Brasil: AC, AM, BA, CE, DF, ES, GO, MG, MS, MT, PE, PR, RJ, RR, SC, SE e SP.

Comentários: reconhecida pelo tamanho reduzido do gametófito, filídios distantes, arredondados, com lóbulos grandes, cobrindo mais de metade do lobo e dente apical alongado, curvo.

Difere de Microlejeunea globosa (Spruce) Steph. pois esta apresenta filídios com lóbulos menores que cobrem menos ou até metade do lobo e oleocorpos grandes, esféricos.

É comum sobre cascas de árvores, em florestas temperadas, matas e restingas, até $2400 \mathrm{~m}$ de altitude (Gradstein \& Costa 2003). Foi coletada sobre troncos na mata úmida, associada com Drepanolejeunea araucariae Steph., Lejeunea flava (Sw.) Nees e Metzgeria herminieri Schiffn.

Figure 18. Microlejeunea bullata. a. Habit of gametophyte, ventral view. b. Habit of gametophyte, dorsal view. c. Lobe and lobule of leaf. d. Lobe dorsal view with ocellus. e. Underleaf (O. Yano \& J. Bordin 29160, SP385538). 
Por apresentar uma ampla distribuição no Brasil e já ter sido citada para Paraná e Santa Catarina, esta nova referência era esperada para o Rio Grande do Sul e sua citação completa uma importante lacuna na distribuição geográfica da espécie.

Microlejeunea globosa (Spruce) Steph., Spec. Hepat. 5:821. 1915. ELejeunea globosa Spruce, Bull. Soc. Bot. France 36(suppl.):193. 1889.

Figura 19

Material examinado: BRASIL. Rio GRANDE do Sul: Caxias do Sul, Centro, sobre tronco de Ligustrum, 14-IV-2006, J. Bordin \& L. Bordin 474p.p. (HUCS28481,
SP383067); Parque dos Macaquinhos, sobre tronco de arbusto, 6-X-2006, O. Yano \& J. Bordin 29217(SP385682); idem, sobre tronco de Lauraceae, 6-X-2006, O. Yano \& J. Bordin 29220p.p. (HUCS29578, SP385685).

Distribuição no Brasil: ES, PA, SC, SE e SP.

Comentários: reconhecida pelo tamanho pequeno do gametófito, pelos filídios com lobos arredondados e lóbulos reduzidos que cobrem menos ou até metade do lobo, com um dente de 1-2(-3) células de altura; anfigastros, bífidos, oblongos.

Difere de Microlejeunea bullata pois esta apresenta filídios com ápices dos lobos arredondados e lóbulos cobrindo grande parte dos lobos.

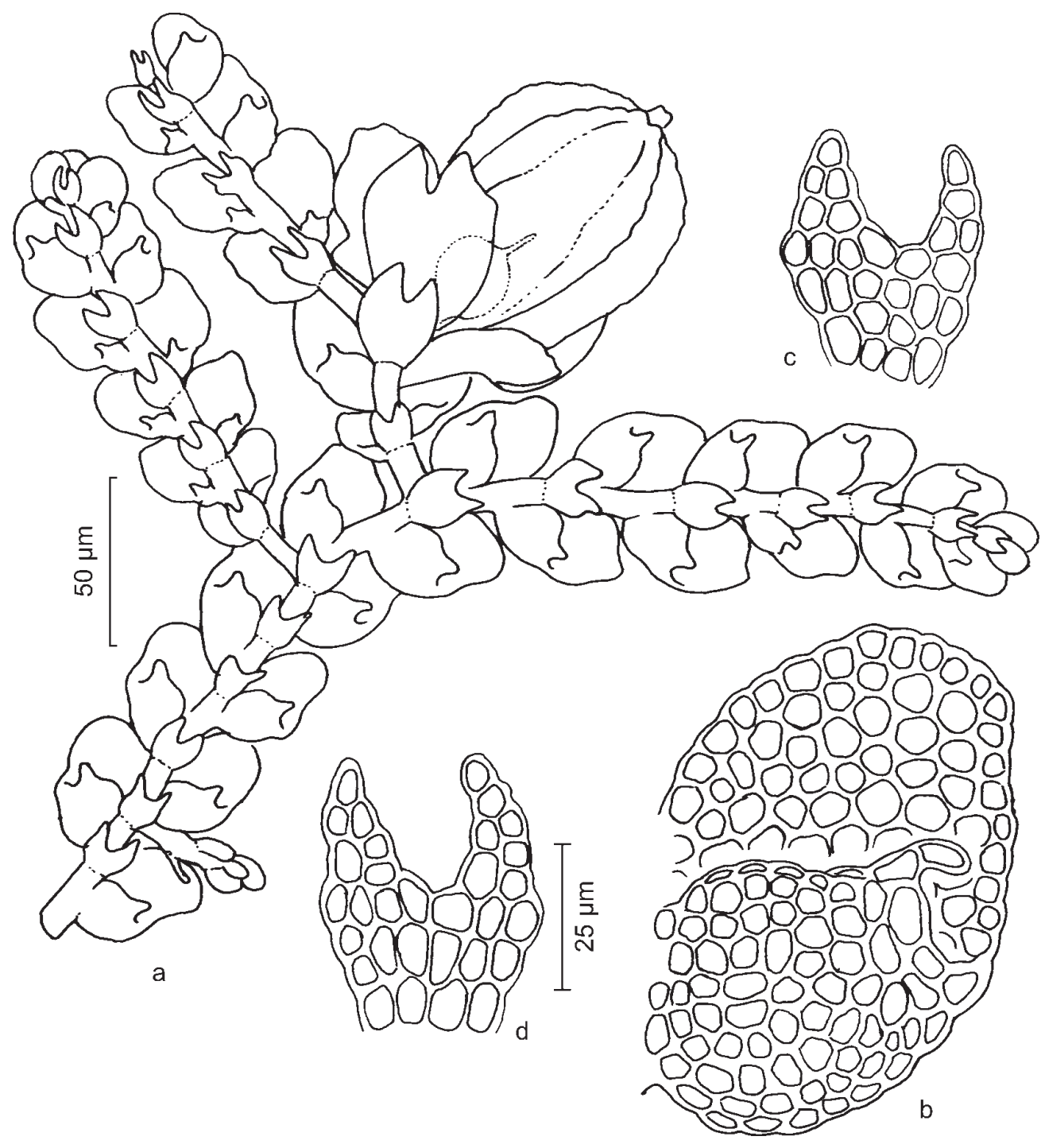

Figura 19. Microlejeunea globosa. a. Aspecto geral do gametófito, vista ventral. b. Lobo e lóbulo do filídio. c, d. Anfigastros (C. Giancotti 575, SP354202).

Figure 19. Microlejeunea globosa. a. Habit of gametophyte, ventral view. b. Lobe and lobule of leaf. c, d. Underleaves $(C$. Giancotti 575, SP354202). 
Ocorre sobre troncos de árvores, em florestas tropicais e restingas, até $1.000 \mathrm{~m}$ de altitude (Gradstein \& Costa 2003). Foi coletada sobre troncos, em parques e ruas urbanizadas, associada com Chonecolea doellingeri (Nees) Grolle, Drepanolejeunea anoplantha (Spruce) Steph. e Frullania ericoides (Nees) Mont. Esta citação amplia a distribuição geográfica da espécie, uma vez que se trata da primeira referência para a região Sul do Brasil.

\section{METZGERIACEAE}

Metzgeria psilocraspeda Schiffn. in Schiffner \& Arnell, Österr. Akad. Wiss. Math. - Naturwiss. Kl. Denkschr. 111:25. 1964.

Figura 20

Material examinado: BRASIL. Rio GRANDE Do Sul: Caxias do Sul, Universidade de Caxias do Sul, na Mata em frente ao MUCS, sobre troncos, 22-XII-2005, J. Bordin et al. 198 (HUCS27289, SP379706); Jardim

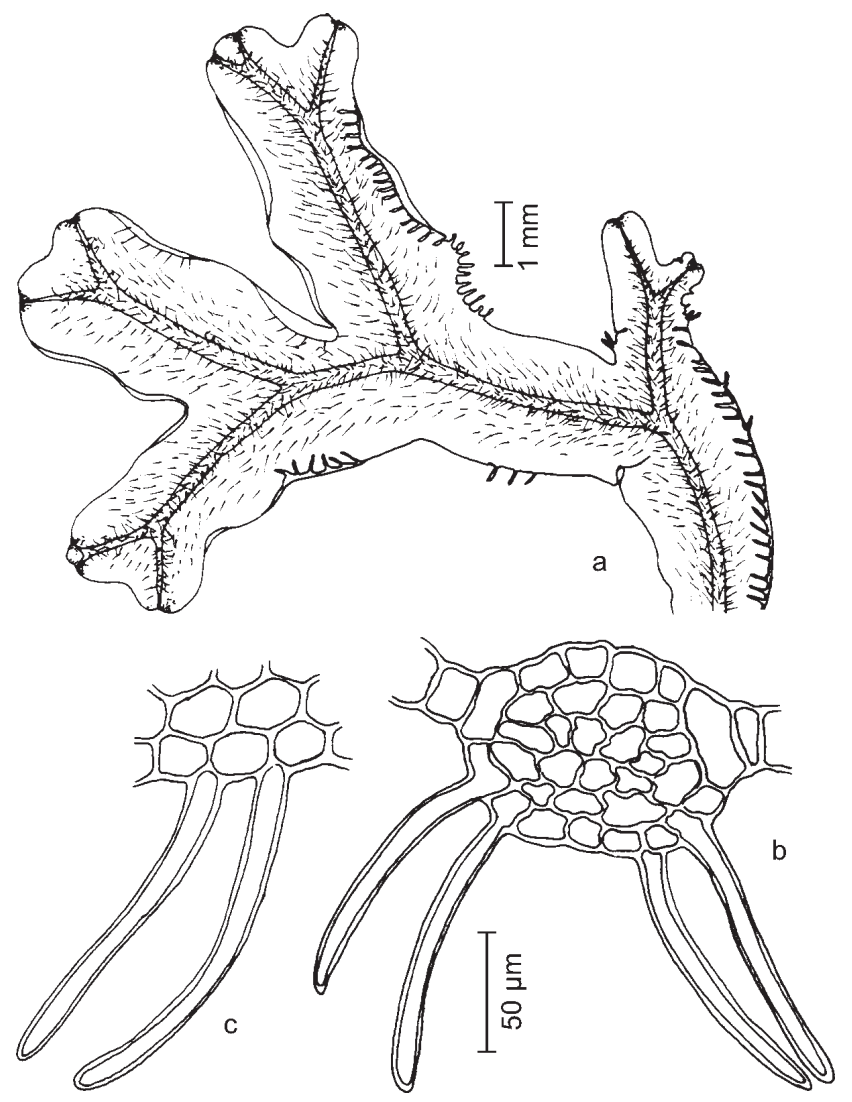

Figura 20. Metzgeria psilocraspeda. a. Aspecto geral do gametófito, vista ventral. b. Secção transversal do talo. c. Rizóides da margem do talo (J. Bordin et al. 198, SP379706).

Figure 20. Metzgeria psilocraspeda. a. Habit of gametophyte, ventral view. b. Cross section of steam. c. Marginal rhizoids (J. Bordin et al. 198, SP379706).
Botânico de Caxias do Sul, sobre tronco de arbusto na beira do riacho, 6-X-2006, O. Yano \& J. Bordin 29253 (SP385718).

Distribuição no Brasil: ES, MG, PR, RJ, SC e SP.

Comentários: reconhecida pelos gametófitos verdeamarelados a castanhos, margem curvada para o lado ventral, região dorsal da lâmina e costa densamente hirsutas, secção transversal da costa com 3-4 fileiras de células epidérmicas dorsais, 5-6 ventrais e medula com 15-22 células, rizóides eretos a levemente falcados, longos, na superfície ventral da costa, lâmina e margem, 1 por célula.

Cresce sobre troncos de árvores vivas, raramente sobre superfície rochosa, até $c a .2000 \mathrm{~m}$ de altitude, predominando na mata atlântica, podendo eventualmente ser encontrada em áreas urbanas (Costa 1999). Foi coletada sobre troncos, na mata úmida.

Metzgeria uncigera A. Evans, Ann. Bot. 24:276. 1910. Figura 21

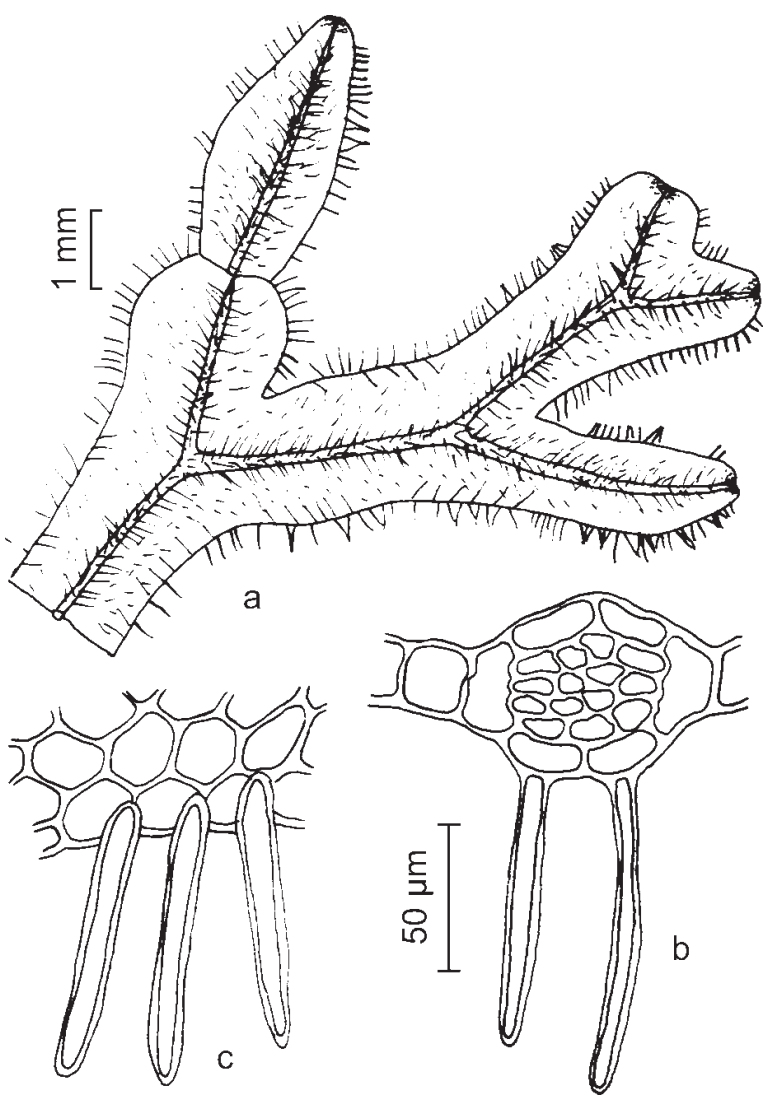

Figura 21. Metzgeria uncigera. a. Aspecto geral do gametófito, vista ventral. b. Secção transversal do talo. c. Rizóides da margem do talo (O. Yano \& J. Bordin 29221, SP385686).

Figure 21. Metzgeria uncigera. a. Habit of gametophyte, ventral view. b. Cross section of thallus. c. Marginal rhizoids (O. Yano \& J. Bordin 29221, SP385686). 
Material examinado: BRASIL. Rio GRANDE Do Sul: Caxias do Sul, Parque dos Macaquinhos, sobre tronco de Ligustrum, 6-X-2006, O. Yano \& J. Bordin 29221 (SP385686). SP.

Distribuição no Brasil: ES, MG, PE, PR, RJ, SC e

Comentários: reconhecida pela secção transversal da costa com 2 fileiras de células epidérmicas ventrais e dorsais, células medulares variando entre 10-12, rizóides na superfície ventral da costa, lâmina e margem, esparsos, 1 por célula.

Foram observadas papilas mucilaginíferas nos ápices dos ramos e as gemas marginais eram escassas, diferindo da descrição de Costa (1999) onde as gemas marginais eram freqüentes e não havia papilas mucilaginíferas. É encontrada sobre troncos e folhas de árvores vivas, como epífila facultativa, entre 500 e $1.200 \mathrm{~m}$ de altitude (Costa 1999), em regiões de alta umidade (Schuster 1992). Foi coletada em parque, em área antropizada.

Entre os Estados das regiões Sul e Sudeste, o Rio Grande do Sul era o único onde M. uncigera A. Evans e M. psilocraspeda Schiffn. ainda não haviam sido citadas. Esta referência, portanto, cobre uma importante lacuna na distribuição geográfica destas espécies.

\section{PELLIACEAE}

Noteroclada confluens (Hook. f. \& Taylor) Spruce, Trans. \& Proc. Bot. Soc. Edinburgh 15:531. 1885, non $N$. confluens Taylor ex W.J. Hooker \& Wilson. $\equiv$ Jungermannia confluens Hook. f. \& Taylor, London J. Bot. 3:478. 1844.

Figura 22

Material examinado: BRASIL. Rio GRANDE do Sul: Caxias do Sul, Centro, Parque Cinqüentenário, paredão de rocha, 3-X-2006, O. Yano \& J. Bordin 29049 (HUCS29469, SP383810); Universidade de Caxias do Sul, no barranco, sobre rocha alterada, 4-X-2006, O. Yano \& J. Bordin 29129 (HUCS29531, SP385507); idem, barranco, sobre solo, 4-X-2006, O. Yano \& J. Bordin 29124 (HUCS29526, SP385502); Jardim Botânico de Caxias do Sul, beira do riacho, no barranco, 12-I-2006, J. Bordin, R. Wasum \& M. Sartori 278 (HUCS27410, SP379515).

Distribuição no Brasil: DF, ES, GO, MG, RJ e SP.

Comentários: reconhecida pelos filídios planos com lobos alargados, complanados e inteiros e os rizóides hialinos ou marrom-claros, cápsulas redondo-ovaladas, normalmente com deiscência irregular, abrindo-se em 4 valvas.

Ocorre em solo úmido ao longo de rios, entre 400$2.500 \mathrm{~m}$ de altitude (Gradstein \& Costa 2003). Foi coletada

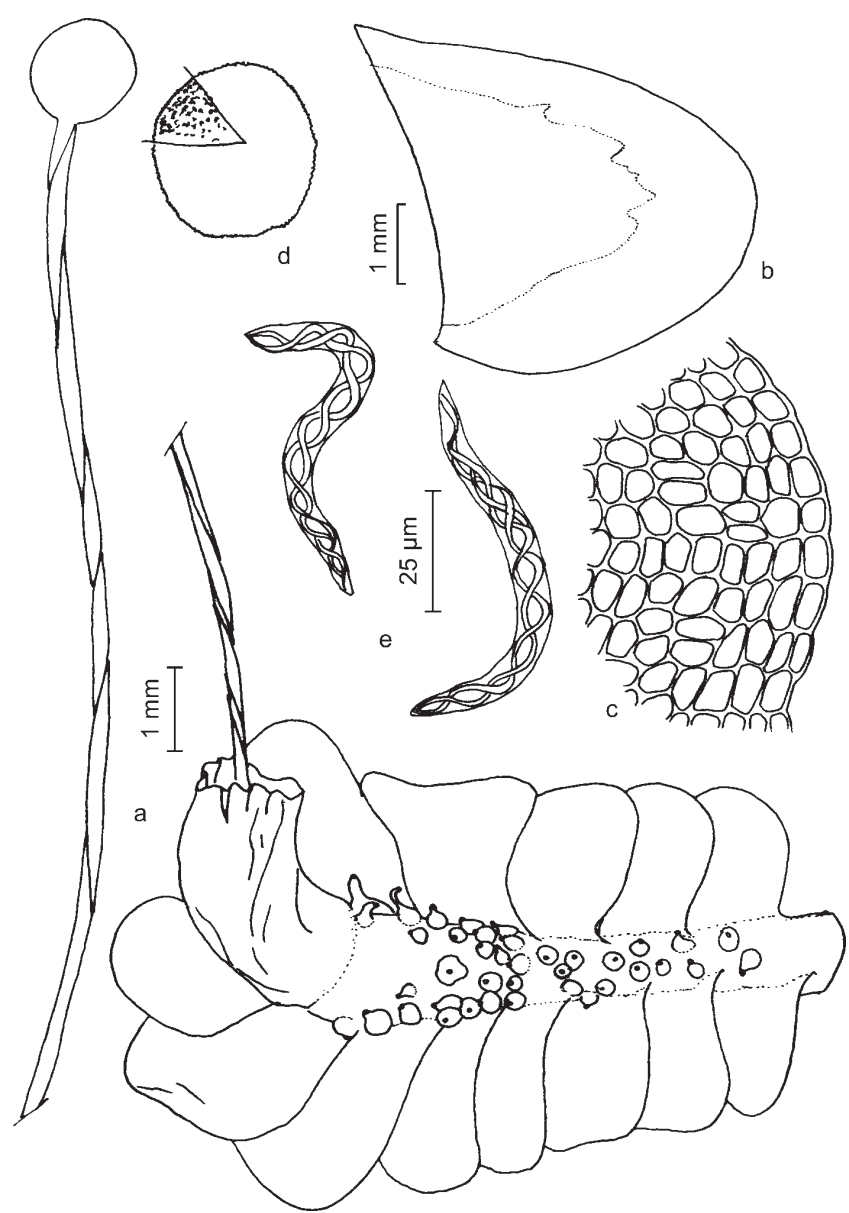

Figura 22. Noteroclada confluens. a. Aspecto geral do gametófito, vista ventral. b. Lobo do filídio. c. Células do ápice do lobo do filídio. d. Esporo. e. Elatérios $(O$. Yano \& J. Bordin 29049, SP383810).

Figure 22. Noteroclada confluens. a. Habit of gametophyte, ventral view. b. Leaf lobe. c. Apex cells of leaf lobe. d. Espore. e. Elaters (O. Yano \& J. Bordin 29049, SP383810).

em parques e beira de mata, sobre rochas e solo, sempre em locais muito úmidos. Esta é a primeira citação para a região Sul do Brasil.

\section{PLAGIOCHILACEAE}

Plagiochila montagnei Nees in Nees \& Mont., Ann. Sci. Nat. Bot. ser. 2, 5:531. 1836.

Figura 23

Material examinado: BRASIL. RIo GRANDE Do SUL: Caxias do Sul, Parque Cinqüentenário, sobre tronco de Sebastiania, 3-X-2006, O. Yano \& J. Bordin 29062 (SP385440).

Distribuição no Brasil: AC, AL, AM, CE, ES, PA, PE, RJ e SP. 


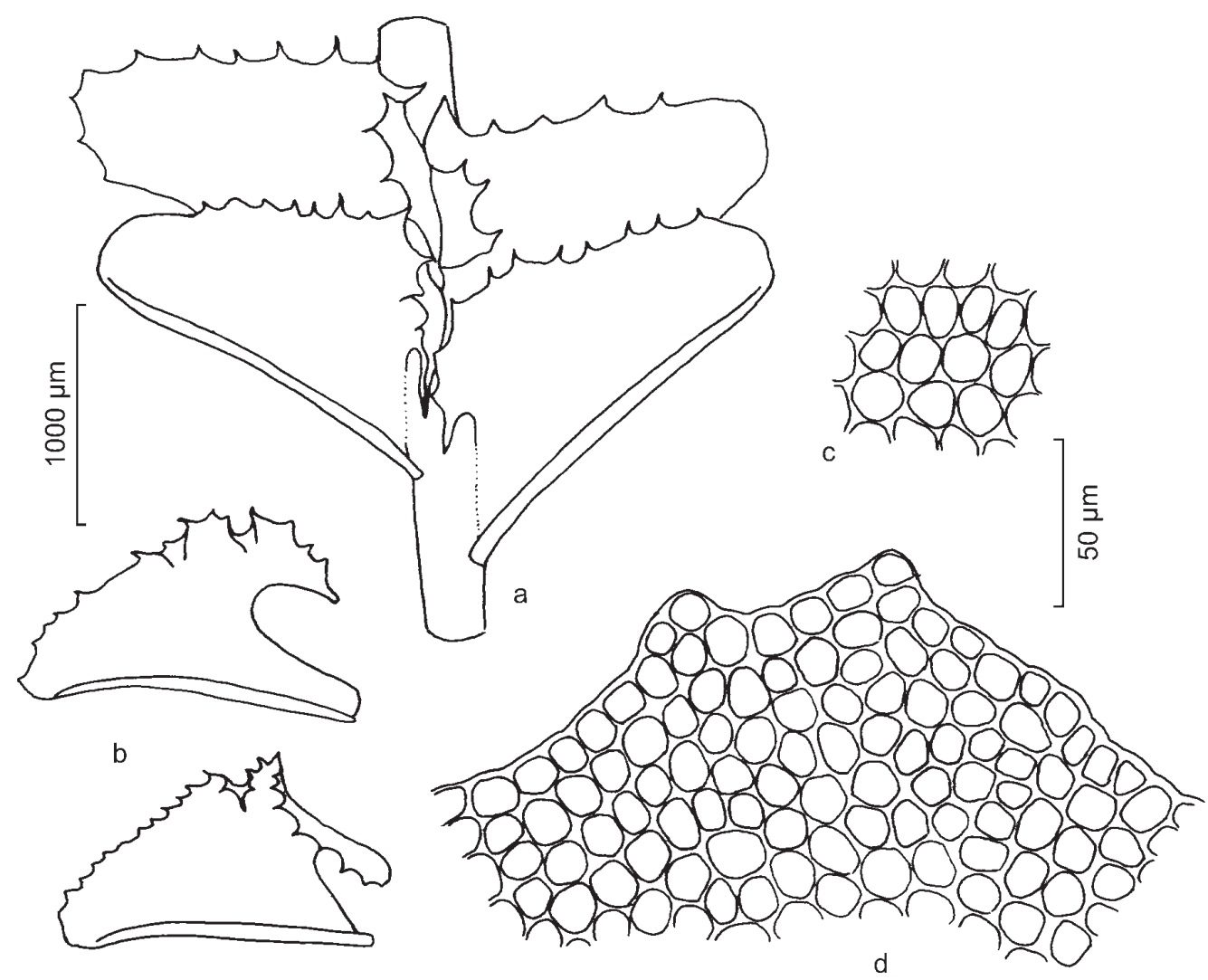

Figura 23. Plagiochila montagnei. a. Aspecto geral do gametófito, vista ventral. b. Lobos dos filídios. c. Células do lobo do filídio. d. Margem do lobo do filídio (O. Yano \& J. Bordin 29062, SP385440).

Figure 23. Plagiochila montagnei. a. Habit of gametophyte, ventral view. b. Leaves lobes. c. Cells of leaf lobe. d. Margin of leaf lobe (O. Yano \& J. Bordin 29062, SP385440).

Comentários: reconhecida pelos gametófitos com ramificações escassas, filídios com margem ventral inteira ou com poucos dentes, curvados e pela margem dorsal com base longo-decurrente.

O material examinado apresenta filídios, especialmente os superiores, com margem ventral lisa e dentes apenas no ápice e outros com dentes curtos em toda a margem, estando de acordo com a descrição de Heinrichs \& Gradstein (2000), onde os dentes, ocasionalmente, podem estar apenas no ápice.

Cresce sobre rochas em planícies e florestas tropicais, até $1.200 \mathrm{~m}$ de altitude (Gradstein \& Costa 2003). Foi coletada sobre troncos, em área antropizada e trata-se da primeira citação para a região Sul do Brasil.

\section{RADULACEAE}

Radula nudicaulis Steph., Spec. Hepat. 4:174. 1910. Figura 24

Material examinado: BRASIL. RIo GRANDE DO SUL: Caxias do Sul, Universidade de Caxias do Sul, na mata, sobre tronco de Sloanea, 3-XII-2005, J. Bordin \& L. Bordin 174p.p. (HUCS27193, SP379849); Jardim Botânico de Caxias do Sul, na mata, sobre troncos, 12IV-2006, J. Bordin, E. Pasini \& T. Ziembowicz 441p.p. (HUCS28005, SP379916).

Distribuição no Brasil: ES, MG, PR, RJ e SP.

Comentários: reconhecida pelos lobos arredondados a orbiculares, lóbulos quadrados que cobrem $c a$. metade a dois terços do caulídio, com margem superior sinuosa, formando pequenas reentrâncias e região carinal inflada.

Cresce sobre cascas de árvores, solo ou rocha, de 800-2700 m de altitude (Gradstein \& Costa 2003). Foi coletada sobre troncos, na mata, associada com Lejeunea phyllobola Nees \& Mont., L. setiloba Spruce, Metzgeria fruticola Spruce e Orthostichella rigida (Müll. Hal.) B.H. Allen \& Magill, Radula nudicaulis Steph. e Schlotheimia jamesonii (W.-Arn.) Brid.

A espécie ocorre nos Estados da região Sudeste e foi citada por Yano (2004) para o Paraná. Esta nova referência amplia a distribuição da espécie, especialmente na região Sul. 


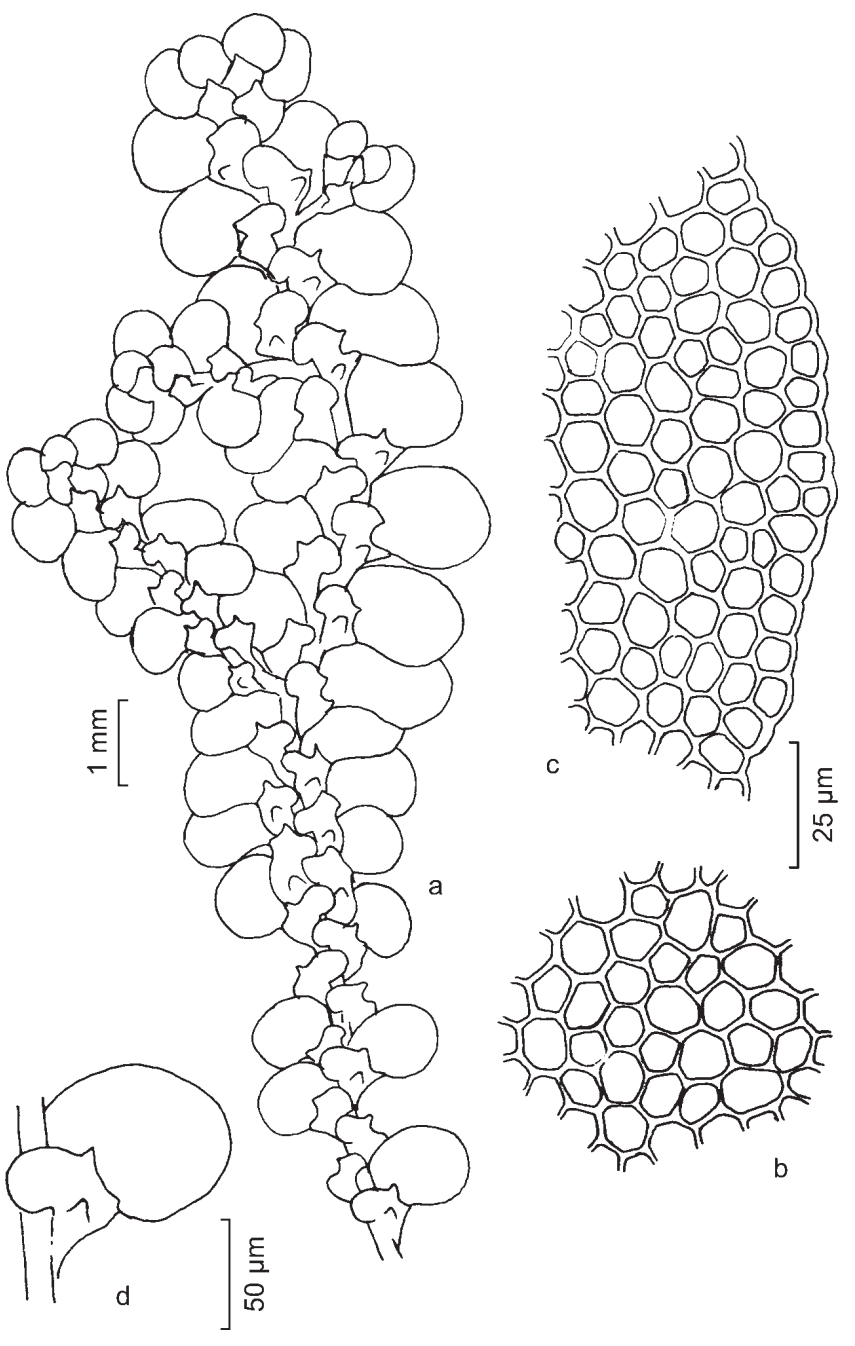

Figura 24. Radula nudicaulis. a. Aspecto geral do gametófito, vista ventral. b. Células do lobo do filídio. c. Células da margem do lobo do filídio. d. Lóbulo do filídio (J. Bordin \& L. Bordin 174p.p., SP379849).

Figure 24. Radula nudicaulis. a. Habit of gametophyte, ventral view. b. Cells of leaf lobe. c. Marginal cells of leaf lobe. d. Leaf lobule (J. Bordin \& L. Bordin 174p.p., SP379849).

Agradecimentos - À Capes pela concessão da bolsa à primeira autora e ao pesquisador Denilson Fernandes Peralta, do Instituto de Botânica pela confecção das ilustrações.

\section{Referências bibliográficas}

BAPTISTA, M.L.L. 1977. Flora ilustrada do Rio Grande do Sul: Lejeuneaceae. Boletim do Instituto de Biociências, Botânica 36:1-135.

BASTOS, C.J.P. 2004. Lejeuneaceae (Marchantiophyta) no Estado da Bahia, Brasil. Tese de doutorado, Universidade de São Paulo, São Paulo.
BASTOS, C.J.P. \& YANO, O. 2006. Lejeuneaceae holostipas (Marchantiophyta) no Estado da Bahia, Brasil. Acta Botanica Brasilica 20:687-700.

BORDIN, J. 2008. Briófitas do centro urbano de Caxias do Sul, Rio Grande do Sul, Brasil. Dissertação de mestrado, Instituto de Botânica, São Paulo.

BUENO, R.M. 1984. Gêneros de Jungermanniales (excl. Lejeuneaceae) no Rio Grande do Sul, Brasil. Dissertação de mestrado, Universidade Federal do Rio Grande do Sul, Porto Alegre.

BUENO, R.M. 1986. O gênero Balantiopsis Mitt (Hepaticopsida) no Brasil. Rickia 13:29-33.

COSTA, D.P. 1999. Metzgeriaceae (Metzgeriales, Hepatophyta) no Brasil. Tese de doutorado, Universidade de São Paulo, São Paulo.

COSTA, D.P. \& YANO, O. 1988. Hepáticas talosas do Parque Nacional da Tijuca, Rio de Janeiro, Brasil. Acta Botanica Brasilica 1:73-82. (supl.)

CRANDALL-STOTLER, B. \& STOTLER, R.E. 2000. Morfology and classification of the Marchantiophyta. In: Bryophyte Biology (A.J. Shaw \& B. Goffinet, eds.). Cambridge University Press, Cambridge, pp.21-70.

FORTES, A.B. 1956. Aspectos fisiográficos, demográficos e econômicos do Rio Grande do Sul. Livraria do Globo, Porto Alegre.

FULFORD, M.H. 1976. Manual of the leafy Hepaticae of Latin América Part IV. Memoirs of The New York Botanical Garden 11:420-485.

GRADSTEIN, S.R. 1975. A taxonomic monograph of the genus Acrolejeunea (Hepaticae) with an arrangement of the genera of Pthychanthoideae. Bryophytorum Bibliotheca 4:1-162.

GRADSTEIN, S.R. 1994. Lejeuneaceae: Ptychantheae, Brachiolejeuneae. Flora Neotropica, Monograph 62: $1-216$.

GRADSTEIN, S.R. \& COSTA, D.P. 2003. The Hepaticae and Anthocerotae of Brazil. Memoirs of The New York Botanical Garden 87:1-318.

GROLLE, R. 1985. Miscellanea hepaticologica. The Journal of the Hattori Botanical Laboratory 58:197-202.

HÄSSEL DE MENÉNDEZ, G.G. 1962. Estudio de las Anthocerotales y Marchantiales de la Argentina. Opera Lilloana 7:1-297.

HÄSSEL DE MENÉNDEZ, G.G. 1989. Las especies de Phaeoceros (Anthocerotophyta) de América del Norte, Sud y Central: la ornamentación de sus esporas y taxonomia. Candollea 44:716-739.

HEINRICHS, J. \& GRADSTEIN, S.R. 2000. A revision of Plagiochila sect. Crispatae and sect. Hypnoides (Hepaticae) in the Neotropics. I. Plagiochila disticha, P. montagnei and $P$. raddiana. Nova Hedwigia 70:161-184.

HELL, K.G. 1969. Briófitas talosas dos arredores da cidade de São Paulo (Brasil). Boletim de Botânica da Faculdade de Filosofia, Ciências e Letras da Universidade de São Paulo 335:11-87. 
LEITE, P.F. \& KLEIN, R.M. 1990. Vegetação. In: IBGE. Fundação Instituto Brasileiro de Geografia e Estatística. Geografia do Brasil: Região Sul. Rio de Janeiro, pp.113-150.

LEMOS-MICHEL, E. 1980. O gênero Frullania (Hepaticopsida) no Rio Grande do Sul, Brasil. Dissertação de mestrado. Universidade Federal do Rio Grande do Sul, Porto Alegre.

LEMOS-MICHEL, E. 1983. Frullania (Jungermanniales, Hepaticopsida) no Rio Grande do Sul. Revista Brasileira de Botânica 6:115-123.

LEMOS-MICHEL, E. 2001. Hepáticas epífitas sobre o pinheiro-brasileiro no Rio Grande do Sul. Editora da Universidade, Porto Alegre.

LEMOS-MICHEL, E. \& BUENO, R.M. 1992. O gênero Bazzania S.F. Gray (Hepaticae) no Rio Grande do Sul, Brasil. Hoehnea 19:143-149.

LEMOS-MICHEL, E. \& YANO, O. 1998. O gênero Bryopteris (Hepatophyta) no Brasil. Acta Botanica Brasilica 12:5-24.

LINDMAN, C.A.M. 1906. A vegetação no Rio Grande do Sul. Typographia da "Livraria Universal" de Echenique Irmãos \& Cia., Porto Alegre.

LORSCHEITTER, M.L. 1973. Hepáticas folhosas primitivas, novas para o Rio Grande do Sul. Iheringia, série Botânica $17: 3-17$.

LORSCHEITTER, M.L. 1977. Flora ilustrada do Rio Grande do Sul. XIII. Lejeuneaceae. Boletim do Instituto de Ciências Biológicas, Série Botânica 36:1-139.

MONTAGNE, C. 1838-1839. Cryptogamae brasiliensis seu plantae cellulares quas in itinere per Brasiliam à celeb. Auguste de Saint-Hilaire collectas recensuit observationibusque nonnulis illustravit. Annales des Sciences Naturelles; Botanique, sér. 2, 11-12:42-55.

MORENO, J.A. 1961. Clima do Rio Grande do Sul. Governo do Estado do Rio Grande do Sul, Secretaria da Agricultura, Porto Alegre.

OLIVEIRA, P.L. 1973. Espécies do gênero Radula Dumortier ocorrentes no Rio Grande do Sul, Brasil (Hepáticas). Iheringia. série Botânica 18:48-53.

OLIVEIRA-E-SILVA, M.I.M.N. \& YANO, O. 2000. Anthocerotophyta e Hepatophyta de Mangaratiba e Angra dos Reis, Rio de Janeiro, Brasil. Boletim do Instituto de Botânica 13:1-102.

RAMBO, S.J.B. 1956. A fisionomia do Rio Grande do Sul. Selbach, Porto Alegre.

REINER-DREHWALD, M.E. 2000. Las Lejeuneaceae (Hepaticae) de Misiones, Argentina VI. Lejeunea y Taxilejeunea. Tropical Bryology 19:81-132.

REINER-DREHWALD, M.E. \& GODA, A. 2000. Revision of the genus Crossotolejeunea (Lejeneaceae, Hepaticae). The Journal of the Hattori Botanical Laboratory 89:1-54.

SCHÄFER VERWIMP, A. \& GIANCOTTI, C. 1993. New or insteresting records of Brasilian bryophytes IV. Hikobia 11:285-292.

SCHUSTER, R.M. 1980. The Hepaticae and Anthocerotae of North America. Columbia University Press, New York, vol.4, 1-1334.
SCHUSTER, R.M. 1992. The Hepaticae and Anthocerotae of North America. Columbia University Press, New York, vol. 6, 1-937.

STOTLER, R.E. \& CRANDALL-STOTLER, B. 2005. A revised classification of the Anthocerotophyta and a checklist of the hornworts of North America, North of Mexico. The Bryologist 108:16-26.

VELOSO, H.P., RANGEL FILHO, A.L.R. \& LIMA, J.C.A. 1991. Classificação da vegetação brasileira, adaptada a um sistema universal. IBGE, Rio de Janeiro.

VIANNA, E.C. 1970. Marchantiales e Anthocerotales coletadas no Rio Grande do Sul, Iheringia. série Botânica 14:45-54.

VIANNA, E.C. 1971. Considerações sobre algumas hepáticas de Gramado, Rio Grande do Sul, Brasil. Iheringia, série Botânica 15:3-17.

VIANNA, E.C. 1976. Marchantiales (Hepaticopsida) coletadas no Rio Grande do Sul. Tese de livre docência, Universidade Federal do Rio Grande do Sul, Porto Alegre.

VIANNA, E.C. 1981a. Sphaerocarpos mucciloi, a new hepatic from Brazil. Lindbergia 7:58-60.

VIANNA, E.C. 1981b. Sobre a ocorrência nova de Monoclea Hook. (Hepaticae) no Rio Grande do Sul, Brasil. Iheringia, série Botânica 26:165-167.

VIANNA, E.C. 1981c. O gênero Riccia (Marchantiales) no Rio Grande do Sul, Brasil. I Subgen. Ricciella e Thallocarpus. Rickia 9:71-80.

VIANNA, E.C. 1985. Flora ilustrada do Rio Grande do Sul. 15. Marchantiales. Boletim do Instituto de Biociências 38:1-213.

VIANNA, E.C. 1988. Donnés additionnalles sur Riccia jovetastiae E.C. Vianna, espècie brésilienne (Rio Grande do Sul). Cryptogamie, Bryologie et Lichénologie 9:73-75.

VIANNA, E.C. 1990. Dados adicionais sobre Riccia fruchartii Steph. Iheringia, série Botânica 40:127-130.

YAMADA, K. 1982. Notes on the type specimens of Radula taxa from Latin America. The Journal of the Hattori Botanical Laboratory 52:449-463.

YANO, O. 1984a. Checklist of Brazilian liverworts and hornworts. The Journal of the Hattori Botanical Laboratory. 56:481-548.

YANO, O. 1984b. Briófitas. In: Técnicas de coleta, preservação e herborização de material botânico (O. Fidalgo \& V.L.R. Bononi, coords.). Instituto de Botânica, São Paulo. Manual n.4. pp.27-30.

YANO, O. 1989. An additional checklist of Brazilian bryophytes. The Journal of the Hattori Botanical Laboratory 66:371-434.

YANO, O. 1995. A new additional annotated checklist of Brazilian bryophytes. The Journal of the Hattori Botanical Laboratory 78:137-182.

YANO, O. 2004. Novas ocorrências de briófitas para vários estados do Brasil. Acta Amazônica 34:559-576.

YANO, O. 2006. Novas adições ao catálogo de briófitas brasileiras. Boletim do Instituto de Botânica 17:1-142. 
YANO, O. 2008. Catálogo de antóceros e hepáticas brasileiros: literatura original, basiônimo, localidadetipo e distribuição geográfica. Boletim do Instituto de Botânica 19:1-110.

YANO, O. \& BORDIN, J. 2006. Novas ocorrências de briófitas para o Rio Grande do Sul, Brasil. Boletim do Instituto de Botânica 18:111-122.
YANO, O. \& COSTA, D.P. 1992. Novas ocorrências de briófitas no Brasil. In (R.R. Sharif ed.). Anais 8응 Congresso da Sociedade Botânica de São Paulo, Campinas, pp.33-45.

YANO, O., MELlO, Z.R. \& COLLETES, A.G. 2003. Briófitas da Ilha de Urubuqueçaba, Santos, São Paulo, Brasil. Iheringia, série Botânica 58:195-214. 